\title{
ONTOLOGY-BASED HBIM FOR HISTORIC BUILDINGS WITH TRADITIONAL WOODWORK IN TAIWAN
}

\author{
Ying-Mei $\mathrm{CHENG}^{1^{*}}$, Chiao-Ling $\mathrm{KUO}^{2}$, Chia-Ching MOU${ }^{1}$ \\ ${ }^{1}$ Civil Engineering and Hazard Mitigation, China University of Technology, Taipei 116, Taiwan \\ ${ }^{2}$ Research Center for Humanities and Social Sciences, Academia Sinica, Taipei 115, Taiwan
}

Received 9 April 2020; accepted 27 November 2020

\begin{abstract}
In recent years, the use of Historic Building Information Modeling (HBIM) has grown prevalent and thus provided a research opportunity. Differing from newly constructed buildings, structural components of historic buildings come with unique physical configurations and have amassed impressive amount of restoration data, all of which must be taken into consideration when incorporating Building Information Modeling. In terms of modelling, it is critical to determine the appropriate level of detail (LoD), level of information (LoI), especially the comprehensiveness and expandability of the database. International Committee for Documentation/Conceptual Reference Model (CIDOC CRM) is a widely accepted standard for ontology model. This study aims to integrate the HBIM and CIDOC CRM to construct a framework and comprehensive operational procedure for the modeling of traditional Minan architecture and a database with complete semantics archiving the background and restoration data. Autodesk A360 is ideal for collaborative. However, there are limitations when it comes to developing advanced models for data management or query; interactive experience; meeting model applications derived from future scenarios. Therefore, the study also offers a 3D modeling platform constructed using Unity, as well as a comparison of the platforms built with Unity, three.js and Autodesk A360 as a reference for users.
\end{abstract}

Keywords: HBIM, CIDOC CRM, historic building, conservation, semantic data, ontology.

\section{Introduction}

Every year, UNESCO singled out natural and cultural landmarks from around the world because of their "outstanding universal value" to humanity (UNESCO, 2020). International conventions such as "Convention Concerning the Protection of the World Cultural and Natural Heritage" are giving these heritage sites more attention and protection to keep them safe from destruction. Each year, countries around the world are trying to win the world heritage site designation for their cultural or heritage sites from UNESCO. However, this designation cannot keep them safe from manmade or natural disasters such as the devastating fires at Notre Dame Cathedral in Paris and Gusuku Sites and Related Properties of the Kingdom of Ryukyu in Japan in 2019. Rapid technological development has put digital conservation technology in a vital position when it comes to the preservation of historic buildings. Such technology is capable of digitally maintaining restoration/reconstruction data, which can be accessed in the event that a historic building is destroyed. The database developed may contain information pertaining to the original shape and material of certain building elements, the restoration techniques applied, the backgrounds of the artisans, and so on. In recent years, advancement in BIM technology has enhanced the ability of public and private entities to handle the complexity and diversity of projects involving digitally archiving historic building records. Logothetis et al. (2015) presented a review of the use of BIM in the field of cultural heritage documentation. They concluded that the diversity and complexity of BIM technology is obvious in many different fields, such as environment, buildings, construction, monument, and structure framework. BIM also integrates both tangible and intangible values as well as external documents into a single model, which serves as a central hub for all information relating to a historic asset (Antonopoulou \& Bryan, 2017). Fadli and AlSaeed (2019) even went as far as designing and establishing the nationwide Qatar Historical Buildings Information Modeling (Q-HBIM) platform.

Many recent studies explore the use of digital technologies in conserving cultural heritage. Historic Building In-

${ }^{*}$ Corresponding author. E-mail: yingmei.cheng@msa.hinet.net 
formation Modeling (HBIM) is a widely recognized modeling approach which integrates 3D models (elements/ components) with construction information such as the shape and size of each element, the background of historic buildings and the expertise of the artisans with a focus on the consistency between historic building information and the 3D parametric model. It can be applied toward documenting materials and construction techniques, providing assistance in the management of conservation efforts as well as the restoration/reconstruction of historic buildings in cases where past records are poorly maintained or no longer in existence. However, the use of this new technology is not without challenges. First, simply trying to digitally document the historic building may be met with obstacles. Due to human or natural factors, the structure may have been modified multiple times and appear far from similar to the original design. Therefore, the modeling efforts must involve advanced technology with high level of precision and detail such as laser scanning and photogrammetry accompanied with thorough literature review. The second challenge arises when trying to systematically define each element in a historic building with proper semantics, and to establish and integrate the relationship between the building elements and relevant information. In other words, it is critical to apply the HBIM technology to simultaneously record both geometric and non-geometric information. Volk et al. (2014) found several challenges of BIM. Extracted here are some points which converge with the perspective presented in this paper: 1) the automation of creating BIM (without preexisting BIM) and capturing the data; 2) undefined LoD for deconstruction functionalities; 3 ) the maintenance and update of information in BIM. This paper aims to provide solutions that address these challenges.

Having been colonized by the Dutch and Spanish in the $17^{\text {th }}$ century, ruled by the Kingdom of Tungning and Qing Dynasty from the late $17^{\text {th }}$ century to early $20^{\text {th }}$ century, and occupied by the Japanese in the first half of the $20^{\text {th }}$ century, Taiwan, the island nation, is left with many historic structures. Based on the 2019 statistics from the Ministry of Culture, there are a total of 941 historic monuments in Taiwan, including ancestral shrines, temples, churches and fortresses. Each comes with different structural framework and characteristics. This paper focuses on a particular branch of traditional structure, the Minanstyle wooden structure, whose origin can be traced to the southern Fujian province in China, and has become symbolic of historic buildings in Taiwan. HBIM is used to construct the model for historic building information and International Committee for Documentation/Conceptual Reference Model (CIDOC CRM) serves as the blueprint to systematically establish the ontology for historic buildings, background information and restoration database. Lastly, a 3D browsing platform for modeling information is established to provide a comprehensive narrative for the complete framework and operational procedure that the conservation of traditional Minan wooden structures should be equipped with. The objectives and phased re-

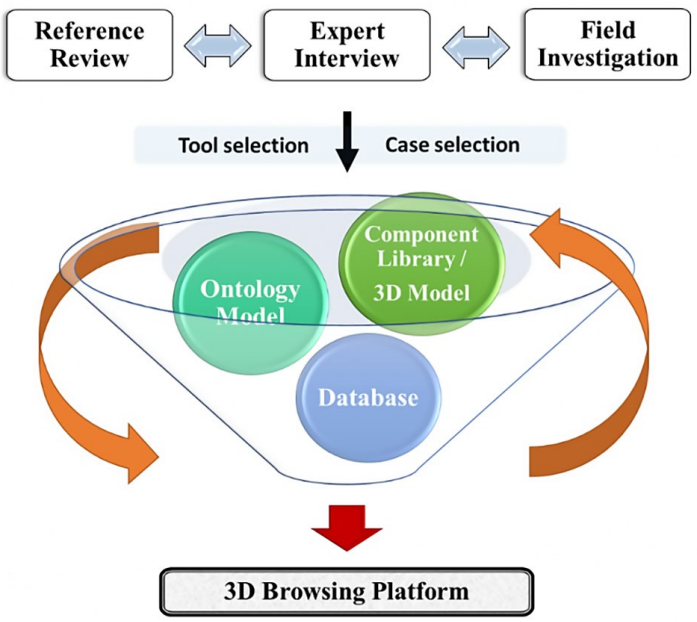

Figure 1. Research process and phased outcome

sults are shown in Figure 1, and the details are provided below:

1. The study proposes the application of ontologybased HBIM to establish comprehensive framework and operational procedure for the conservation of traditional Minan structure.

2. Huangxi Academy from central Taiwan is chosen as the case study. Its wooden building components are disassembled and categorized in a systematic format with characteristics of each component analyzed. HBIM is then used to establish the component library in the building information model and to complete the $3 \mathrm{D}$ model for the entire historic building.

3. CIDOC CRM is used as the reference to create the ontological model. The model integrates the historic building information model and restoration records on the historic building components to complete the database framework containing background and restoration information.

4. To meet different requirements for different modeling approaches, different $3 \mathrm{D}$ browsing platforms may be needed. The ultimate goal for this study is to establish the database with a 3D browsing platform using Unity and three.js. A comparison of platforms created with Unity, three.js and Autodesk A360 (https://a360.autodesk.com/) is conducted to provide recommendations for choosing the proper platform to search for background information and restoration records on building components.

Researchers continue to make progress in the innovation of automated and semi-automated modeling: Tang et al. (2010) dealt with as-built BIM; Thomson and Boehm (2015) worked on BIM from point clouds; Barazzetti (2016) used point cloud data for heritage modelling; Antón et al. $(2018,2019)$ focused on the semi-automatic as-built modelling for HBIM and accurate analyses; and Moyano et al. (2020) applied HBIM to create parametric objects in archaeology (A-BIM). Boeykens et al. (2012) noted that "virtual reconstruction itself is not new". They 
concluded that the modeling process is influenced by personal decisions, experience and expertise. Research objectives 1 and 2 proposed the comprehensive framework and operational procedure for regional historic buildings and established a component library for such buildings. During the process, the complexity of traditional Minan building structure must be taken into consideration. That includes how the building structure is disassembled and components defined. For example, if the definition of the component unit is too small, the modeling process will be time-consuming. On the other hand, if the definition is too large, the model may fail to provide the necessary information for reconstruction. Therefore, research objectives 1 and 2 are expected to strike a balance between the completeness of and the time spent on modeling. The component library can also be used for subsequent modeling. Further research into HBIM is with the incorporation of ontology (Acierno et al., 2017; Quattrini et al., 2017; Dezen-Kempter et al., 2018; Yen \& Lu, 2019; Previtali et al., 2020). Scholars focusing on CIDOC CRM, such as Dezen-Kempter et al. (2018), Yen and Lu (2019), Previtali et al. (2020), point out that HBIM information can be presented more comprehensively and systematically with CIDOC CRM. Research objective 3 aims to complete the database framework for background and restoration information for the historic building components using CIDOC CRM. Yen and Lu (2019) once discussed HBIM with LoI (Level of Information) for the life cycle of historic buildings from a conceptual and top-down perspective. Yen and $\mathrm{Lu}$ (2019) divide the life cycle into 3 phases - Investigation/Designation; Rehabilitation; Management. According to their definition, objective 3 addresses phases I and II from a bottom-up perspective, and pays more attention to the modeling process and the connection between the components and semantic data. The intent of objective 4 is to create a $3 \mathrm{D}$ browsing platform with Unity. However, considering the fact that Logothetis and Stylianidis (2016) once encouraged the utilization of open source software (OSS) for documenting cultural heritage, and the accessibility and convenience offered by Autodesk A360, a comparison is also offered in this study to evaluate platforms generated with 3 different software options - Unity, three.js and Autodesk A360. The paper is organized as follows: Section 1 - literature review; Section 2 - methodology; Section 3 - case study (Huangxi Academy); Section 4 - application of HBIM in Huangxi Academy; last section - conclusion.

\section{Literature review}

There are quite a number of HBIM-related studies around the world, including Murphy et al. (2009), Banfi (2017), Banfi et al. (2017), Pöchtrager et al. (2017) and Barazzetti et al. (2017). Most of them focus on ways of accelerating the construction of the 3D model for historic buildings with higher precision. Hichri et al. (2013) indicates that in order to establish a highly effective digital presentation of a historic building, it is crucial to analyze and comprehend the complete process from extracting the $3 \mathrm{D}$ point cloud to establishing a well-structured 3D digital model with rich semantics. Basilica di Santa Maria di Collemaggio in L'Aquila AQ, Italy is the first HBIM case utilizing advanced 3D measurement. The parametric modeling improved the quality and management during the restoration efforts after the 2009 earthquake (Barazzetti et al., 2014). Brumana et al. (2014) utilized drone video, laser scanning and Revit (https://www.autodesk.com/products/revit/ overview) to conduct post-earthquake maintenance and conservation for Basilica Santa Maria di Collemaggio, and adopted NURBS to build the models for the north wall. Meanwhile, the structural software, MIDAS, is applied to run the Finite Element Method in order to understand the effects that the earthquake has on the particular component. Nieto Julián et al. (2016) used Palace of Charles $\mathrm{V}$ as a case study and built a model using laser scanning and ARCHICAD. The study demonstrates the use of point cloud and ARCHICAD to document the maintenance records for sculpted bricks and tiles. Chiabrando et al. (2016) studied the town, Pollenzo. Using laser scanning, the research builds the model using the plug-in of Revit to extract the contour of the point cloud semi-automatically, and construct a model with complicated curvatures with ARCHIDCAD. Dhanda et al. (2017) analyzed and compared the characteristics of the common modeling simulation software. In addition, a small number of studies mentioned the significance of information in HBIM. For instance, Han et al. (2017) point out that HBIM can be used as the framework of index for tangible cultural heritage. Banfi (2017) stresses that the development of BIM mainly gears toward the establishment of information management system, as well as the importance of new concepts such as Grade of Generation (GoG), Grade of Information (GoI) and Grade of Accuracy (GoA). Brumana et al. (2013) utilize LiDAR and photogrammetry to reconstruct historic buildings. Aside from building the 3D models, the approach takes the historic information of the historic buildings into consideration, and include them in HBIM. Fregonese et al. (2015) use LiDAR scan for the modeling of historic buildings and separate that from the attributes. The component attribute information (basic attributes in Revit) is saved in the database for future applications and editing, and BIM3DSG is used to view the 3D model. The attribute database is plugged into BIM3DSG to display datasets for both the model and attributes. However, the attributes here refer to the basic component information rather than cultural attributes. Acierno et al. (2017) propose that there is a connection between the subject and ontology for the study on architectural heritage. There are four domains - Artefact Domain, Artefact Lifecycle Domain, Architectural Heritage Investigation Process Domain and Actors Domain. It is evident that comparing to newly constructed buildings, information concerning historic buildings or architectural heritage are much more complicated. In addition to architectural and civil engineering professionals, experts in archeology, medicine, chemistry and biology are also involved. Antonopoulou 
and Bryan (2017) offered a guidance for owners, end-users and professionals in the fields of heritage and construction by raising awareness of the potential advantages of a BIM approach. In the 2018 paper on the review of HBIM, López et al. (2018) mentioned "only a few research deals with the automation of the reverse engineering process, as well as the processes of interoperability, management, documentation, and maintenance of the 'as-is model' building".

\section{Methodology}

In addition to establishing the component library of historic buildings with a systematic approach, the study also establishes an ontological model and database for background information as well as restoration records for historic buildings. A browsing platform for the $3 \mathrm{D}$ model is then completed to provide a comprehensive discourse of the framework and operational procedure, which can be representative of projects dealing with the conservation of traditional Minan style wooden structures. The modeling flow chart, methods and tools are shown in Figure 2. The methodology and tools applied for each stage are described in the following sections.

\subsection{D Modeling}

Regular 3D modeling process can be done through the conventional surveying and drawing, and with the help of laser scanning. The drafting process is illustrated in Fig- ure 3. The upper part is the so-called reverse-engineering modeling process, which generally includes the following tasks: 1) Data capture; 2) Segmentation of point clouds; 3) Classification of the regions identified in the segmentation step; and 4) Reconstruct the 3D model (Buonamici et al., 2018), while the conventional modeling approach (bottom half of Figure 3 ) is called the top-down modeling approach, which completes floor plans and elevations in CAD through the traditional surveying and drawing method, and CAD separates the individual components to be imported into Revit to construct the components for historic buildings. Currently, many scholars have proposed semi-automatic as-built approaches, hoping to obtain accurate $3 \mathrm{D}$ models more effectively to represent the actual protection status of historic buildings so that these assets can be accurately analyzed. However, the emphasis of this study is to systematically deconstruct the historic building structure into independent components carrying their own background and restoration information, which does not require a high LoD. In the case of building exteriors, the details can be better presented through a linked image or video. Nevertheless, a minimum LoD for the structural components must be maintained. Based on general requirements for the LoD of BIM models in AEC, LoD 300 is chosen to build the 3D model using the manual theoretical modeling approach. At LoD 300, the geometric shapes of the components can be clearly identified and do not need to meet the fineness requirements for construction drawings or other applications which require further analysis. The study utilizes Revit and the

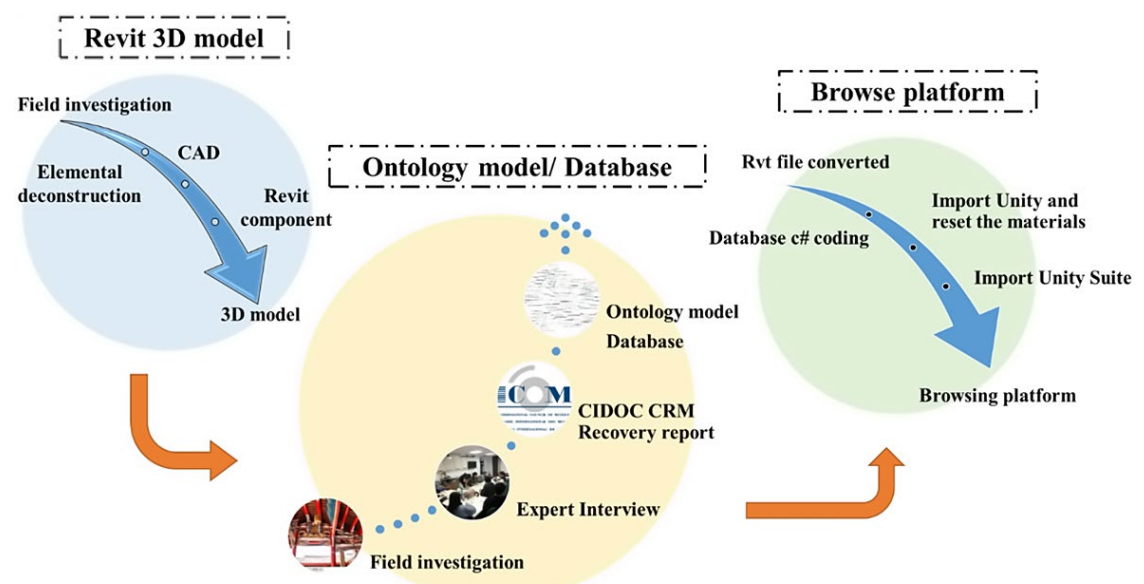

Figure 2. Modeling flow chart, methods and tools

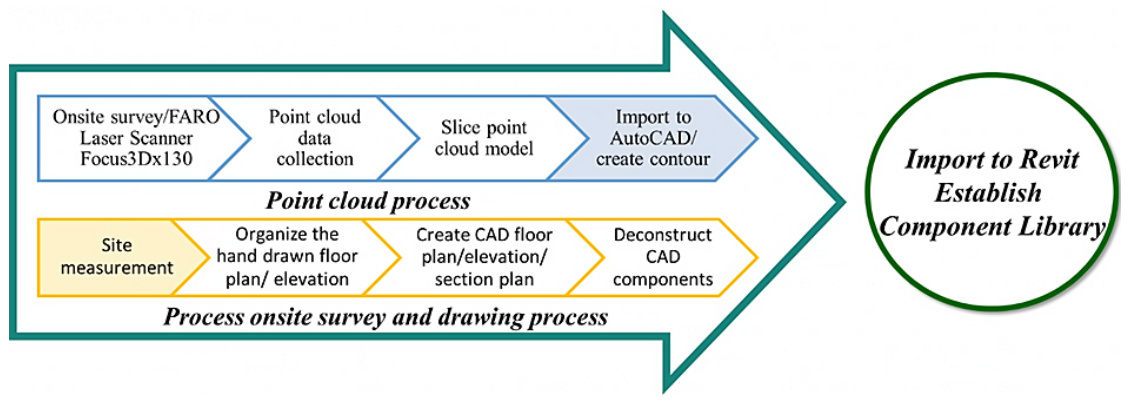

Figure 3. 3D modeling procedure 
conventional modeling approach to integrate the model with a point cloud file in order to identify the spatial location of the components. During the modeling process, the parametric component library is also established for the wooden structures.

\subsection{Ontology and CIDOC CRM}

It is crucial to determine ways of systematically integrating and establishing 3D models for historic buildings and maintaining the information, especially for presenting descriptions of restoration and restoration records individual on building components of traditional architecture. The adoption of ontology is essential in order to present the information in a methodical and comprehensive manner and connect to the global communities by using the common language, and to ensure pertinent updates as time progresses. Ontology is typically applied toward deductive reasoning regarding the attributes of a field in which one is interested. It can also be applied toward defining a specific field for which the model is established. For ontological models, CIDOC CRM (http://www.cidoc-crm. org/) is a widely accepted and promoted standard. It is able to expand the standardized ontological model and has received ISO 21127:2006 certification in 2006 (International Organization for Standardization [ISO], 2006), which was revised in 2014 (ISO, 2014). It can be regarded as the common language shared among the field experts and implementers.

CIDOC CRM is the conceptual reference model established by the International Committee for Documentation (CIDOC) under International Council of Museums (ICOM). It is a formal ontology intended to facilitate the integration, mediation and interchange of heterogeneous cultural heritage information. The intent is to allow for exchange and integration of information on heterogeneous cultural heritage among different countries and different languages, providing definition for languages and categories so that regionalized information can be transformed into universal resources across the globe. Specifically, formal ontology defines and limits the basic semantics of the database model and document structure used within cultural heritage and museum documents. Its objective is not to propose the content that cultural institutions should document. Rather, it explains the logic behind the documentation, which in turn realized the interoperability of the semantics. CRM is meant to support the specific functions below (ICOM/CIDOC, 2019):

1. Serve as guidelines for developers of the information system for best practice of conceptual modeling to effectively construct and connect information related to cultural heritage.

2. Serve as the common language for field experts and IT developers, and enable them to have accurate understanding of the relevant cultural information as well as be consistent in terms of identifying needs and establishing system functions.

3. Serve as the official language for identifying common information content among different data formats. In particular, support the automatic data conversion from local data structure to global data structure without losing its meaning.

4. Support queries related to resource integration through the integration of basic classes and connected global model.

The ontology established through the form and structure of CRM is expandable. Users from various fields may establish and expand the ontological model to fit the needs tailored to certain fields. In order to connect with the international community, this study adopts standardized ontological model based on CIDOC CRM to establish the model for historic Minan wooden structures. It is the hope to more effectively document and present cultural information related to the historic building. Currently, Protégé, which is developed by Stanford University, is the most commonly used tool for establishing the ontological model. The software, which is applied in multiple fields, is capable of establishing massive visual ontological models with various presentation formats. This is helpful towards the understanding of connections among components. Protégé is the software of choice for establishing the ontological model in this study.

\subsection{Database and query platform}

Prior to establishing the database, several interviews were conducted with field experts. The interviews were held in the form of official advisory meetings with 4 to 8 experts invited to each meeting. These experts include architects who have been in the field of historic preservation for more than 10 years; contractors specializing in conservation of historic structures; university professors who have conducted years of research in the field of ontological methodology. The experts discussed several issues during each project stage, including the definitions of architectural components and their names; ways of deconstructing the components; information to be embedded within the components; the framework of CIDOC CRM. After each meeting concluded, expert opinions were compiled with project modification made accordingly. Additionally, restoration reports of historic wooden buildings are also referenced to classify the historic building information and establish the relation structure of the data sets. Key comments provided by field experts are stated below:

1. The components are titled with terms currently used in Taiwan, including Minan and Hakka terms. Terms used in China and historical terms from the Song and Qing dynasties are not included in this paper.

2. The components are classified based on how the 3D model will be integrated. The components are categorized based on functions first, and divided into vertical and horizontal components from bottom to the top. Identical components may receive alternative names when the form varies. To avoid confusion, the alterative names are not considered. 
3. Deficiencies of the field functions should be addressed to cover both practical and theoretical purposes. Subforms should be provided for attributes, such as construction methods, tools and materials. The worksheets can be linked through key values to perform crosstab query afterwards.

4. The LOD of a model can be affected by human factors at times. Models of several structural components commonly used for traditional Minan structures have been created for this study, and they can be applied towards other projects simply by modifying internal parameters to minimize human-induced discrepancies. In the future, more common component models will be created to make this methodology more widely accepted.

5. LoI should be changed to LoD to explore differences among different levels, the content to be included, and how to determine corresponding descriptions for the components as well as background or restoration information.

Typically, one can add attributes/information needed during building restoration to the newly added elements while creating 3D models with Autodesk Revit. As the modeling process completes, so does the restoration database. In Revit, each element is assigned a unique code, which is what links the attributes/information and the element itself. When the completed 3D model is uploaded to A360, the query function is ready. As a user-friendly software, Autodesk A360 is ideal for collaborative tasks where members across all teams may review the same $3 \mathrm{D}$ model or examine information pertaining to certain structural components. However, the scope of query conducted by directly clicking the elements on a 3D model is limited. The lack of data structure and planning cannot accommodate querying functions across multiple applications. Additionally, attaching the attributes directly onto the element ID may lead to overly large files that run the risk of causing system crash during the query process. Due to these reasons, the authors attempt to establish a separate database and browsing platform for the restoration records rather than constructing the database in the same Revit file, which may be cumbersome to the maintenance efforts or future expansion. It is also the hope that in addition to conducting data browsing through the $3 \mathrm{D}$ model, the model may also accommodate basic data query.

The information platform for the $3 \mathrm{D}$ model is developed with Unity and three.js. Unity is an inter-platform game engine used to develop single player games for Windows, MacOS and Linux systems, or iOS and Android mobile systems. Three.js is a cross-browser script that uses JavaScript function libraries or APIs to create and display animated 3D computer graphics in a web browser. TWAMP is used to develop the database for the $3 \mathrm{D}$ model of Huangxi Academy. TWAMP provides phpMyAdmin, a PHP-based database management tool constructed on the mainframe in a web-based format. It allows administrators to manage MySQL database through the web interface.

\section{Case study}

Huangxi Academy` is the oldest structure remaining in Dadu District of Taichung, Taiwan. Being the cultural and educational center of the community in the past, Huangxi Academy has over 130 years of history. The construction of Huangxi Academy was commissioned to artisans from the so-called San-yi region (Jingjiang, Nanan, Huian) in Quanzhou, China. The architecture is representative of the Huian style during the late Qing dynasty (16331912), which is characterized by the enclosed courtyard layout. Its significance in terms of architectural heritage is paramount. Intricate craftsmanship can be found in the construction materials, styles and techniques. The traditional building has a double-square layout and a courtyard separating the front and back. The width of the building is about 28 meters. The depth is approximately 30 meters. The spatial layout starting from the outside includes shanman (front gate), courtyard, baidian (hall of worship), main hall (lecture hall), east and west chambers, and connecting hallways. Building materials include red brick tiles, granite, bluestone and China-fir. The spatial layout and current status of Huangxi Academy is shown in Figure 4 . The main structures include the main hall and hall of worship. The details are described as follows:

1. Front gate (shanman): Shanman refers to the entry gate of a Buddhist temple. It is also known as "three gates (also pronounced 'shanman' in Mandarin)". In Buddhism, the term is a metaphor for the three ways (gates) that lead to liberation - liberation through emptiness (sunyata), liberation through the absence of perpetual attributes (animitta), and liberation through wishlessness (apranihita).

2. Hall of worship (baidian): In Taiwanese temples, baidian refers to the structure directly in front of the main hall where the main presiding deity is worshipped.

3. Main hall (lecture hall): Main hall refers to the structure centrally located within a palatial or temple complex. It is where the main presiding deity is placed. It is also typically the tallest and largest structure within the complex.

4. East and west chambers: In a residential complex, the east and west chambers are two symmetric rows of structures built on each side of and parallel to the main central axis. They are used mostly as the kitchen or sleeping quarters for the more junior members in the family. The Hakka calls them heng $w u$ (horizontal structure). In Kinmen and Punghu areas, they are referred to as ju tou (side chambers).

5. Connecting hallways: The connecting hallways refer to the pathways connecting the main hall and hulong (wing), or between various wings. Sometimes they are structured like a pavilion, which allows the water to pass through underneath and provides shelter from the rain. It is also referred to as $\mathrm{Gu}$ oshui Ting (Passing Water Pavilion). 


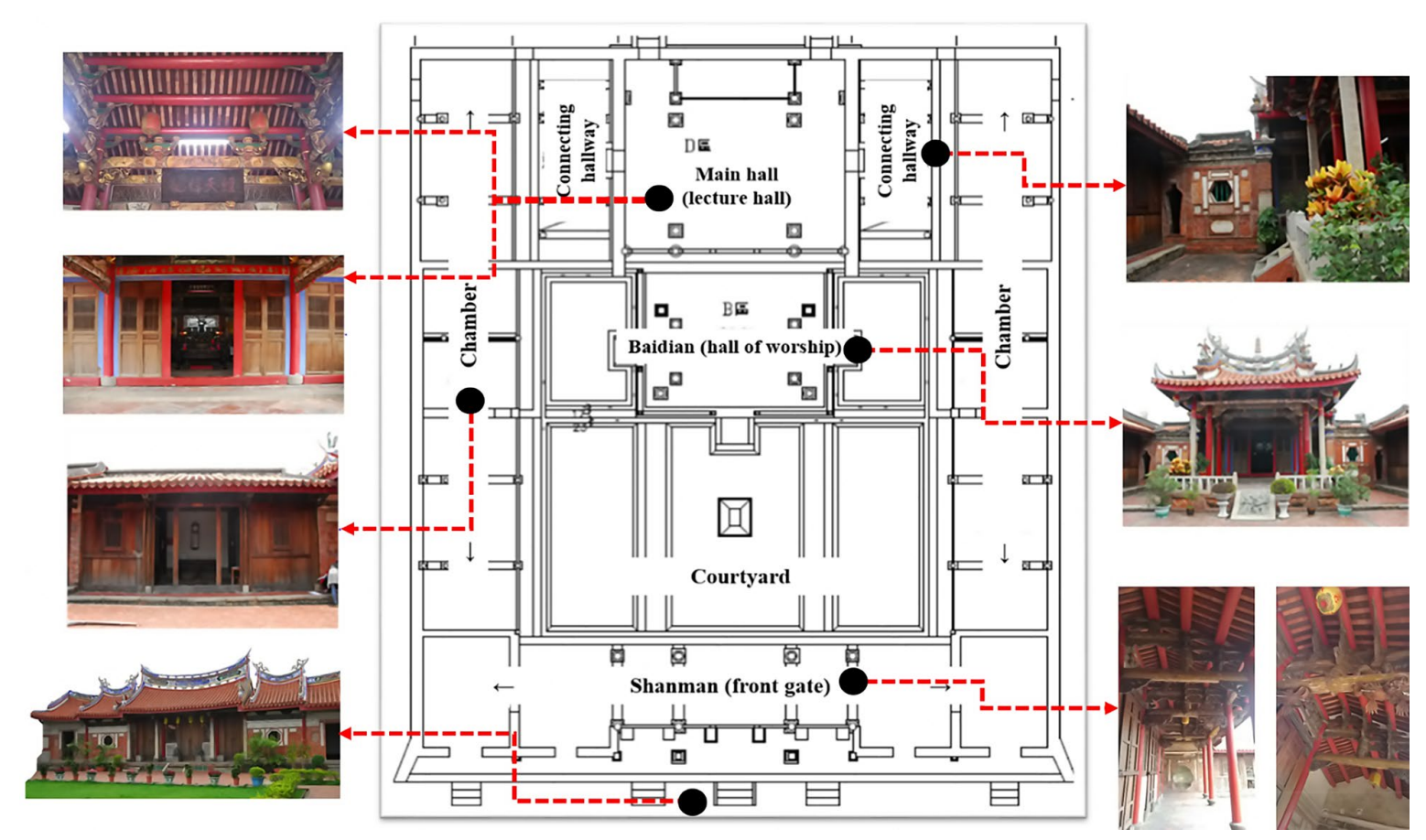

Figure 4. Spatial layout and current status of Huangxi Academy

In 1984, Dadu Township Office in Taichung County commissioned Han Guang Architectural Firm to conduct the first survey study on Huangxi Academy. The first restoration project undertaken by Han Guang Architectural Firm took place between 1986 and 1989. In 2000, the Ministry of the Interior approved the funding for restoration. And the restoration of the hall of worship and the main hall was conducted by Cultural Affairs Bureau, Taichung County in 2002. The roof over shanmen (front gate) was restored between 2005 and 2006. After three survey and renovation projects, Huangxi Academy finally returns to its formal glory. The historic building has significant historic and architectural values, and is a precious cultural heritage. The restoration records are listed in Table 1 (Yen, 2018; National Cultural Heritage Database Management System, 2020).

\section{Application}

To study Huangxi Academy, onsite surveys historical records, point cloud files, pictures and videos for the onsite building components are compiled. Wooden components are isolated individually to build the Revit component and construct the 3D model. Building components are identified and named while drawing their 3D counterparts. The framework of the restoration report and CIDOC CRM manual served as references to establish the ontological model and database. The Revit model output is then converted into FBX files to be imported into Unity, where the material is then reset. The restoration database and report are consulted for C\# coding, and imported into Unity to establish the query platform for restoration records.

\subsection{Component library and 3D model for case study}

The market offers many BIM options, among which are Autodesk Revit, Tekla and ArchiCAD. Each comes with unique characteristics and functions. Revit, which is built with the grouping concept, offers comprehensive functions, such as defining attributes, which is helpful for recording restoration information. Autodesk also provides A360, which offers a common platform for multiple team members to collaborate on and management the same project on the cloud, making it easier for users to browse through background information from the Revit 3D model. Revit has been chosen to create the components and 3D model for this project, in which, RFA files are family files that can either be uploaded into a project or saved externally. This is a crucial quality for building component libraries that can be applied toward similar projects.

Historic wooden structures consist of large numbers of building components, which are classified for the purpose of this study. The basic principles for the classification are: 1) Starting from the front of the building to the back along the main axis of the building; 2) Classifying all trusses on the structure from the exterior to the interior, from the front to back and from the left to right; 3) From the lowest building component under the truss, identifying every interval at different height. Additional details can be found in Cheng et al. (2018a). In order to convert them into Revit components systematically without any omissions, the components must be coded properly. The site layout is divided into Front Gate (A); Hall of Worship (B); Main Hall (C); East and West Chambers (D); 
Table 1. Restoration records on Huangxi Academy (source: compiled from Huangxi Academy restoration report and meetings with field experts)

\begin{tabular}{|c|c|c|c|c|}
\hline $\begin{array}{l}\text { Restoration } \\
\text { period }\end{array}$ & Restored space & Artisans & Methods & Tools \\
\hline 1986-1989 & $\begin{array}{l}\text { - Front gate } \\
\text { - Hall of worship; } \\
\text { - Connecting } \\
\text { hallway; } \\
\text { - Newly built; } \\
\text { front chambers; } \\
\text { - Rear chambers }\end{array}$ & $\begin{array}{l}\text { - Major woodwork: } \\
\text { Chen o-Fu, Li o-E, Lin } \\
\text { o-Zhong, Chen o-Shan, } \\
\text { Zhang o-De; } \\
\text { - Wood carving: Cai } \\
\text { o-Cheng, Yan o-Yi, } \\
\text { Huang o-Fa, Xu o-Fu; } \\
\text { - Masonry: Xiao o-Yuan, } \\
\text { Song o-Qin, You o-Gen, } \\
\text { Wen o-Ji; } \\
\text { - Roof tile work: Xiao } \\
\text { o-Yuan, Song o-Qin; } \\
\text { - Clay sculpture and } \\
\text { applique: Cheng o-Hua, } \\
\text { Li o-Huang, Lin o-Song; } \\
\text { - Brick and tile work: You } \\
\text { o-Chong; } \\
\text { - Brick sculpture: You } \\
\text { o-Chong; } \\
\text { - Wall construction: Wen } \\
\text { o-Ji }\end{array}$ & \multirow[t]{3}{*}{$\begin{array}{l}\text { - Major woodwork; } \\
\text { - Wood carving; } \\
\text { - Masonry; } \\
\text { - Roof tile work; } \\
\text { - Clay sculpture and } \\
\text { applique; } \\
\text { - Brick and tile work } \\
\text { - Brick sculpture; } \\
\text { - Wall construction }\end{array}$} & \multirow[t]{3}{*}{$\begin{array}{l}\text { - Major woodwork: plywood, cardboard, } \\
\text { steel square, chalk line, flexible curve } \\
\text { ruler, tape measure, electric planer, } \\
\text { electric knife sharpener, chainsaw; } \\
\text { - Wood carving: Chisels, scroll saw, } \\
\text { sharpening stone, power drill; } \\
\text { - Masonry: threads, plumb bob, trowels, } \\
\text { triangle hammer, steel plate, large iron } \\
\text { bucket, spade, tape measure, wheel } \\
\text { barrow, and crane; } \\
\text { - Roof tile work: Trowels, greyboard, } \\
\text { mortar mixing bucket; } \\
\text { - Clay sculpture and applique: wire, barb } \\
\text { wire, steel bar, metal trowel, small iron } \\
\text { bucket; } \\
\text { - Brick and tile work: electric engraver, } \\
\text { stone ax, iron hammer, knife, water jet } \\
\text { cutter, plumb bob, and sponge; } \\
\text { - Brick sculpture: electric engraver } \\
\text { set, chisels, iron hammer, chisel set, } \\
\text { sharpening stone; } \\
\text { - Wall construction: threads, plumb bob, } \\
\text { water jet cutter, metal trowel, triangular } \\
\text { hammer, spade, wheelbarrow, manual } \\
\text { crane, pen brush, chalk line, tape } \\
\text { measure, template, wooden ruler. }\end{array}$} \\
\hline $2002-2002$ & $\begin{array}{l}\text { Main hall and } \\
\text { worshipping hall }\end{array}$ & Construction Company & & \\
\hline $2006-2007$ & $\begin{array}{l}\text { Restoration of } \\
\text { the roof over } \\
\text { Sanchuan Hall at } \\
\text { the front gate }\end{array}$ & Construction Company & & \\
\hline
\end{tabular}

Note: In order to protect personal information, this table omits a part of the name of the artisans.

Connecting Hallway (E). The letters in the parentheses are the codes assigned for each area. They are followed by serial numbers to indicate the component name and type. The components established for Huangxi Academy include parametric universal components - tong (main beam), dou (supporting bracket) and ying (roof beam); non-parametric universal components - shumu (connecting beam), column base (zuzhu), shusui (decorative Shu bracket), guatong (gourd-shaped supporting bracket). Figure 5 shows that all components of Hall of Worship are classified into either parametric or non-parametric components. In the code, B010418, for example, B represents the area, Hall of Worship; 01 is the code for plinth; 04 is the code for the 4th type, referring to the fourth type of plinth in the hall of worship; 18 indicates that this is the 18th plinth after entering the front gate.

To allow these components to be transferrable for other projects, most of them are created as RFA file. Basically, the component types are divided into the three following classifications based on how each component would be utilized in the model. They are family component with parameters, family component without parameters and custom component (Cheng et al., 2018a). During the drawing process, building components that appear in high frequency, such as B13 tong (main beam), B14 dou (sup- porting bracket) and B15 ying (roof beam), are defined as family component with parameters, whose geometric parameters can be established. The bottom of Figure 5 shows the parameters and various sizes of the B14 supporting brackets. Others, such as tuomu (angle bracket), guatong (gourd-shaped supporting bracket), roof and fence, are complicated in form. It is difficult to establish the parameters so they are defined as family component without parameters or custom component. Such designation allows for systematical conversion of the common Minan architectural components into the component library with parametric attributes pre-established in Revit. The components can be applied repeated during the modeling process. Table 2 shows how regular components correspond to the built-in Revit components for Huangxi Academy.

Center for Cultural Sites Rehabilitation and Development provided the point cloud, drafts of floorplans and elevations of Huangxi Academy. The RCP file is linked with the 3D model to support the identification of spatial position. Figure 6 shows the point cloud of Huangxi Academy and Figure 7 shows the layering of shanman and point cloud as well as the final assembly. All of the established components are loaded into the Huangxi Academy project and assembled. Figure 8 shows the completed model for Huangxi Academy. 


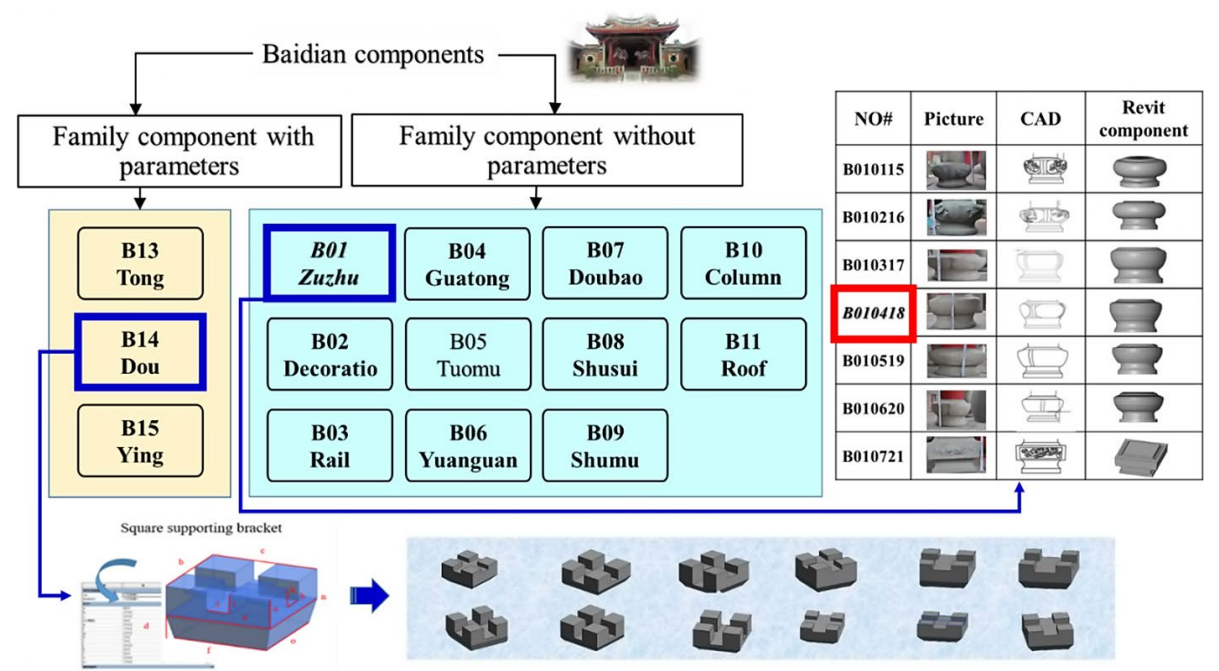

Figure 5. Types of components in hall of worship
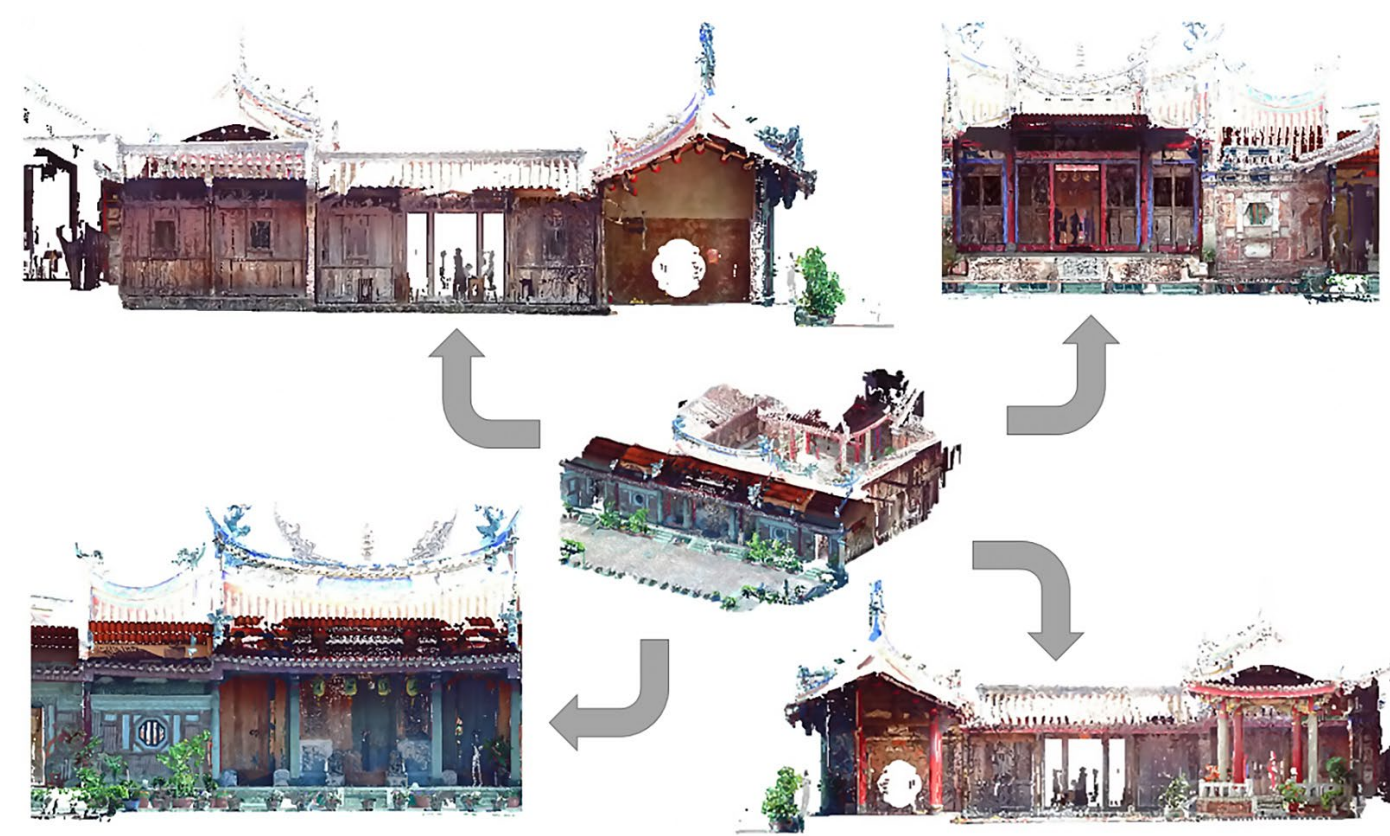

Figure 6. Point cloud of Huangxi Academy

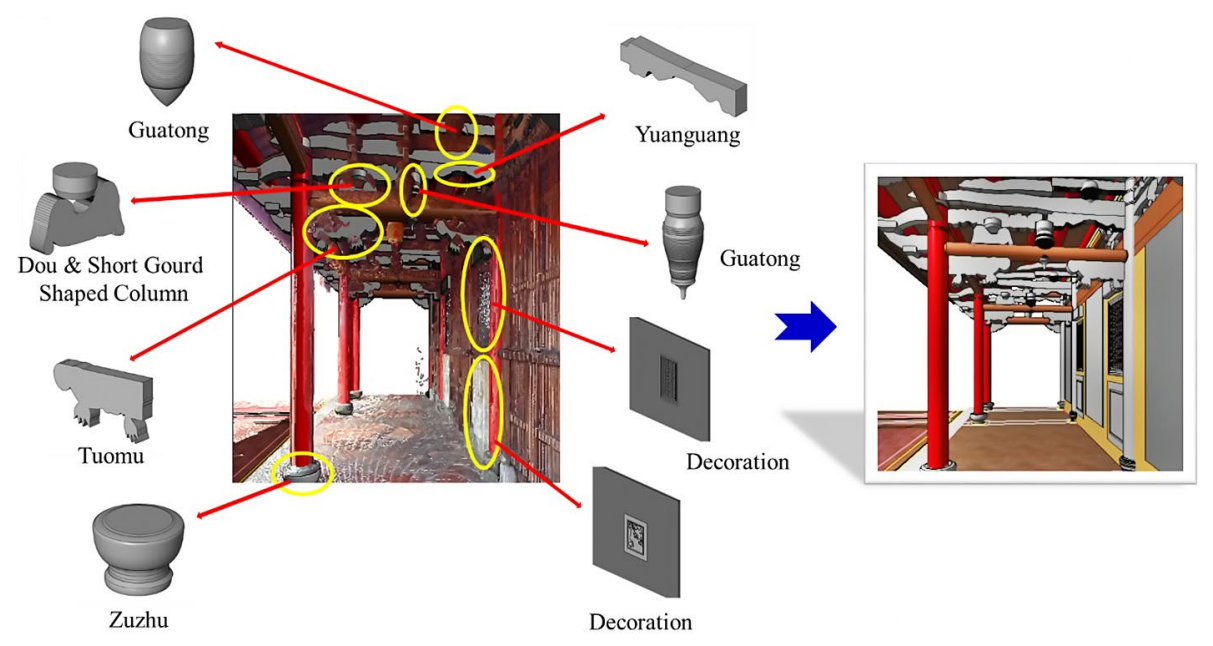

Figure 7. Layering of Shanman components with point cloud, and final assemblage (partial) 


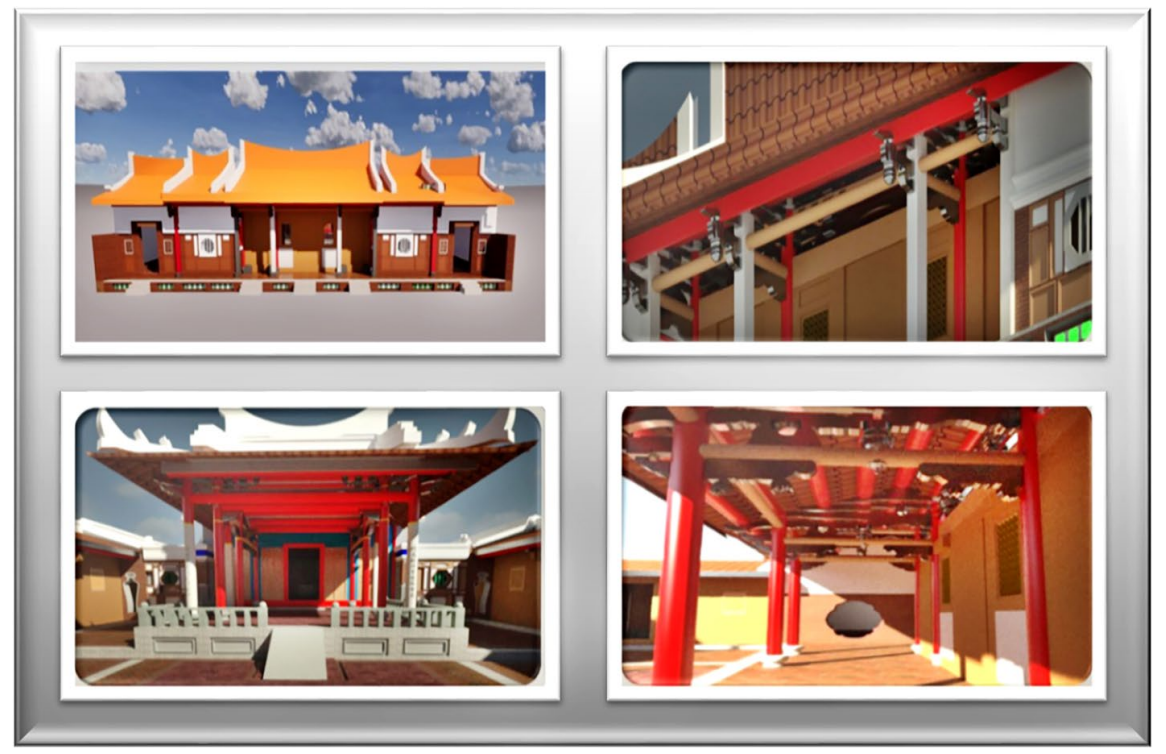

Figure 8. Finalized Revit model of Huangxi Academy

Table 2. Common building components of traditional Minan architecture and corresponding Revit components

\begin{tabular}{|c|c|}
\hline Name in Revit & Commonly used components \\
\hline $\begin{array}{l}\text { Column \& related } \\
\text { family }\end{array}$ & $\begin{array}{l}\text { Qianjinzhu (Front Golden Column), Houjinzhu (Back Golden Column), Diaotong (Short Hanging Column), } \\
\text { Guazu (Gourd Shaped Column), Guatong (Short Gourd Shaped Column), Zuzhu (Column Base) }\end{array}$ \\
\hline $\begin{array}{l}\text { Beam and related } \\
\text { family }\end{array}$ & Shumu (Connecting Beam), Tong (Main Beam), Ying (Roof Beam) \\
\hline $\begin{array}{l}\text { Bracket related } \\
\text { family }\end{array}$ & $\begin{array}{l}\text { Shusui (Decorative Shu Bracket) } \\
\text { Shuwei (Protuding end of Shu Bracket) } \\
\text { Kansui (Decorative Kan Bracket) } \\
\text { Yuanguang (Decorative Connecting Bracket) } \\
\text { Yuanguangji (Protruding end of decorative connecting bracket) } \\
\text { Toujin (Top Connecting Bracket) } \\
\text { Yidoushansheng (One beam with three brackets) } \\
\text { Tuomu (Angle bracket) } \\
\text { Dou (Bracket) }\end{array}$ \\
\hline Wall & Use the built-in function to change the dimension and materials, and rename. \\
\hline Floor & Use the built-in function to change the dimension and materials and rename to, for instance, grass. \\
\hline Roof & $\begin{array}{l}\text { The front, middle and back roofs over the connecting hallways, the left, middle and right roofs of the front } \\
\text { gate, and the roof over the hall of worship. }\end{array}$ \\
\hline
\end{tabular}

\subsection{Ontological model for restoration records of historic buildings}

Huangxi Academy Restoration Report (Yen, 2018) and Guji Tujieshidian (A Pictorial Guide for Historic Sites) by Professor Chien-Lang Lee (Lee, 2003) are referenced for this paper. Several experts were also consulted during multiple meetings to establish the taxonomy for the building components in the component library. The meetings also include discussions on items and component related information to be included in the ontological model. Three ontological models are established for this study:

1. Basic information concerning the building components of the historic building: name, survey information, units, dimensions, materials, and so on.

2. Artisans: This is a human-centric approach to determine information to be included, for example, an artisan's expertise and personal information.
3. Restoration records: Determine information to be included based on the type of information required for restoring the historic building, for example, the name of the building component, construction method, measurement units and the type of disaster that had caused damages.

In order to be consistent with the international community, the ontological model in this study is established with the CIDOC CRM framework as reference. And Protégé is used to establish the ontological model for the hall of worship of Huangxi Academy. Set the relationship in "object property" as $\mathrm{P}$ and "class" is set as E, as indicated in Tables 3 and 4. Under "individual", set the information regarding the artisan, restoration time as well as material or dating of components based on the restoration records of Huangxi Academy. The final ontological models are shown in Figures 9 to 11. 
Table 3. CIDOC CRM property name included in each object property hierarchy

\begin{tabular}{|c|c|c|}
\hline Bas & Art & tion records \\
\hline $\begin{array}{l}\text { P1 is identified by (identifies) } \\
\text { P2 has type (is type of) } \\
\text { P3 has note } \\
\text { P4 has time-span (is time-span of) } \\
\text { P43 has dimension (is dimension of) } \\
\text { P45 consists of (is incorporated in) } \\
\text { P48 has preferred identifier (is preferred identifier of) } \\
\text { P53 has former or current location (is former } \\
\text { or current location of) } \\
\text { P67 refers to (is referred to by) } \\
\text { P71 lists (is listed in) } \\
\text { P78 is identified by (identifies) } \\
\text { P87 is identified by (identifies) } \\
\text { P90 has value } \\
\text { P91 has unit (is unit of) } \\
\text { P92 brought into existence (was brought into } \\
\text { existence by) } \\
\text { P93 took out of existence (was taken out of existence by) }\end{array}$ & $\begin{array}{l}\text { P1 is identified by (identifies) } \\
\text { P2 has type (is type of) } \\
\text { P3 has note } \\
\text { P4 has time-span } \\
\text { (is time-span of) } \\
\text { P41 classified (was classified by) } \\
\text { P42 assigned (was assigned by) } \\
\text { P53 has former or current } \\
\text { location (is former or current } \\
\text { location of) } \\
\text { P71 lists (is listed in). } \\
\text { P78 is identified by (identifies) } \\
\text { P87 is identified by (identifies) } \\
\text { P92 brought into existence } \\
\text { (was brought into existence by) } \\
\text { P93 took out of existence (was } \\
\text { taken out of existence by) }\end{array}$ & $\begin{array}{l}\text { P2 has type (is type of) } \\
\text { P3 has note } \\
\text { P4 has time-span (is time-span of) } \\
\text { P7 took place at (witnessed) } \\
\text { P16 used specific object (was used for) } \\
\text { P33 used specific technique } \\
\text { (was used by) } \\
\text { P34 concerned (was assessed by) } \\
\text { P35 has identified (was identified by) } \\
\text { P67 refers to (is referred to by) } \\
\text { P71 lists (is listed in) } \\
\text { P78 is identified by (identifies) } \\
\text { P87 is identified by (identifies) } \\
\text { P92 brought into existence (was brought } \\
\text { into existence by) } \\
\text { P93 took out of existence (was taken } \\
\text { out of existence by) }\end{array}$ \\
\hline
\end{tabular}

Table 4. CIDOC CRM class name included in each class hierarchy

\begin{tabular}{|l|l|l|}
\hline \multicolumn{1}{|c|}{ Basic items } & \multicolumn{1}{|c|}{ Artisan } & \multicolumn{1}{c|}{ Restoration records } \\
\hline E1 CRM Entity & E1 CRM Entity & E3 Condition State \\
E18 Physical Thing & E17 Type Assignment & E5 Event \\
E41 Appellation & E39 Actor & E14 Condition Assessment \\
E42 Identifier & E41 Appellation & E29 Design or Procedure \\
E47 Spatial Coordinates & E42 Identifier & E48 Place Name \\
E48 Place Name & E45 Address & E49 Time appellation \\
E49 Time appellation & E49 Time appellation & E53 Place \\
E53 Place & E52 Time-Span & E55 Type \\
E54 Dimension & E53 Place & E41 Appellation \\
E55 Type & E55 Type & E47 Spatial Coordinates \\
E57 Material & E62 String & E49 Time appellation \\
E58 Measurement Unit & E63 Beginning of Existence & E63 Beginning of Existence \\
E60 Number & E64 End of Existence & E64 End of Existence \\
E62 String & & E71 Man-Made Thing \\
E63 Beginning of Existence & & E89 Propositional Object \\
E64 End of Existence & &
\end{tabular}

\subsection{Establishment of information platform}

The setting for the fields within the database is established based on expert opinions and data collected. The fields for component names and basic component information, such as model ID, names, physical location and dimension (as shown in Table 5), as well as the fields for component restoration records, such as time, degree of damage, tool, restoration method (as shown in Table 6) are categorized into char, varchar and int for the corresponding types based on the data type to finalize the database. Once constructed, the database allows users to conduct queries through the worksheets, which covers the names and descriptions of the components, external links and material types, etc. The queries may be combined with SQL. An example is to query using the description, external reference ID and materials of the hanging bracket. In worksheet e1, which contains information on external resources of the component, External Reference E42 indicates the component ID in Revit. Figure 12 shows the query process and outcome. As the historic building undergoes restora- tion, the data may be updated. In terms of maintenance, it would be easier than maintaining the built-in attributes within Revit.

A VR platform is established using Revit and Unity to allow users to search for restoration records of the historic building within the VR domain as well as maintain and manage the historic building. The main reason behind choosing Unity to develop the platform is that the software allows the user to customize the content of the tables using c\# so that essential attributes related to the historic building can be added and irrelevant attributes are left out. To those engaging in restoration efforts, this software allows for added flexibility, and users are able to choose the appropriate platform based on actual needs. Figure 13 shows the flowchart of the platform establishment process. In addition to the computer platform, Unity is also compatible with mobile platforms such as Apple iOS (https://www.apple.com/ $t w /$ ) and Google Android (https://www.android.com/), handheld game consoles such as 3DS and PSV, and TV game console such as Xbox One (https://www.xbox.com/ $z h-T W /$ ) and PS4 (https://www.playstation.com/cht-tw/). 


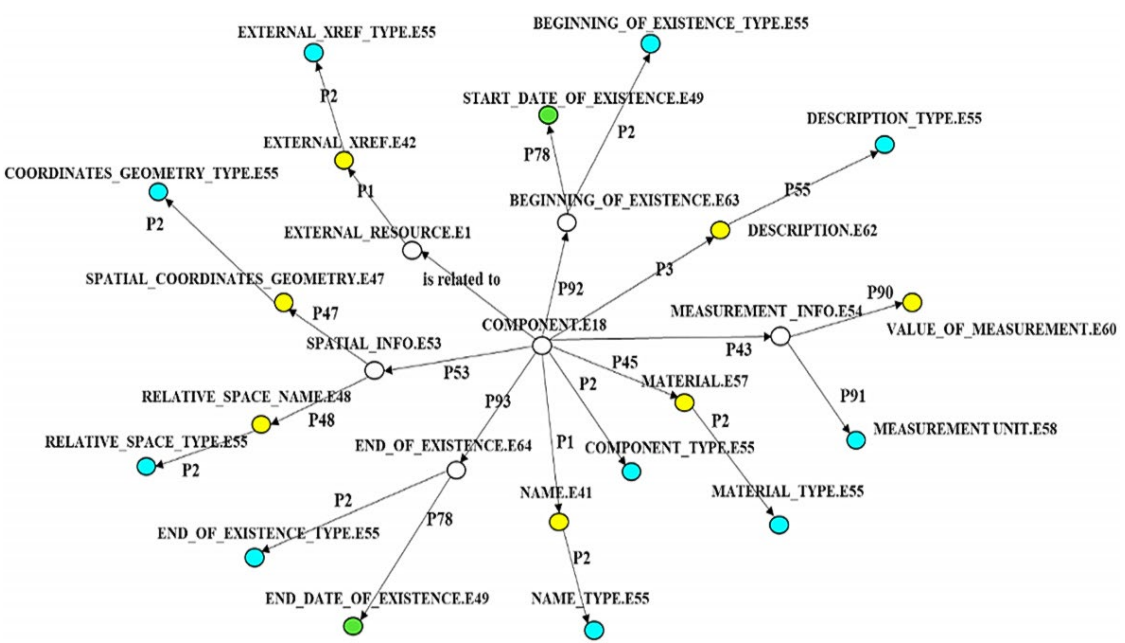

Figure 9. Overview of ontological model for background information

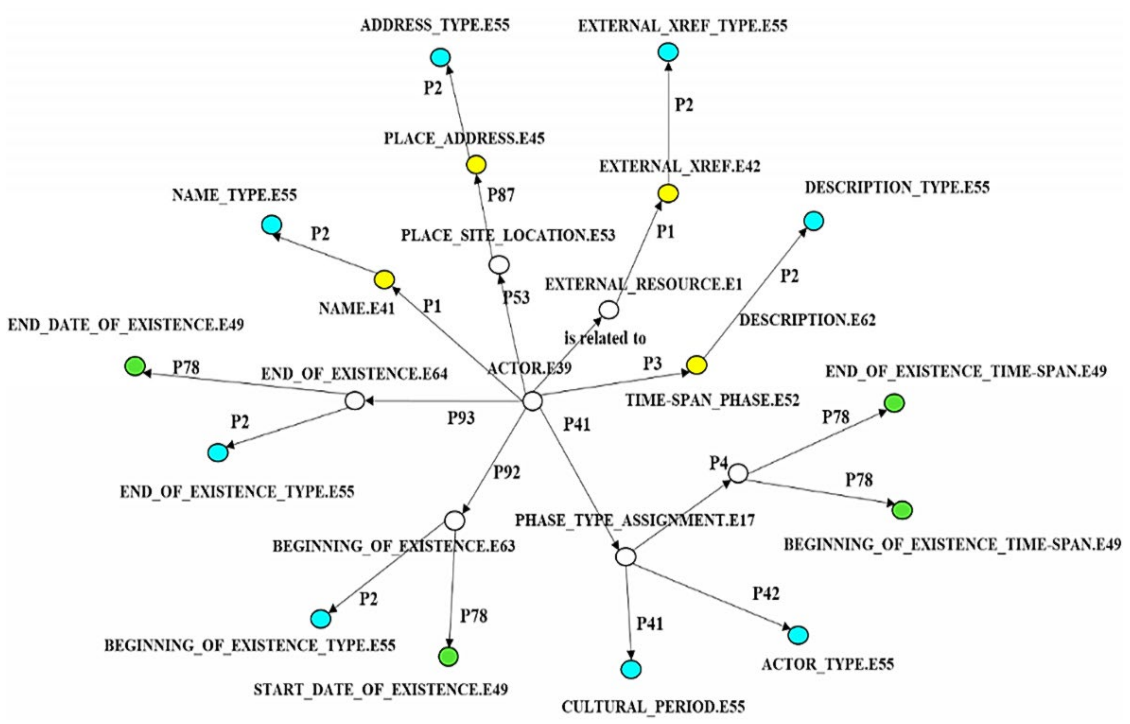

Figure 10. Overview of ontological model for artisan information

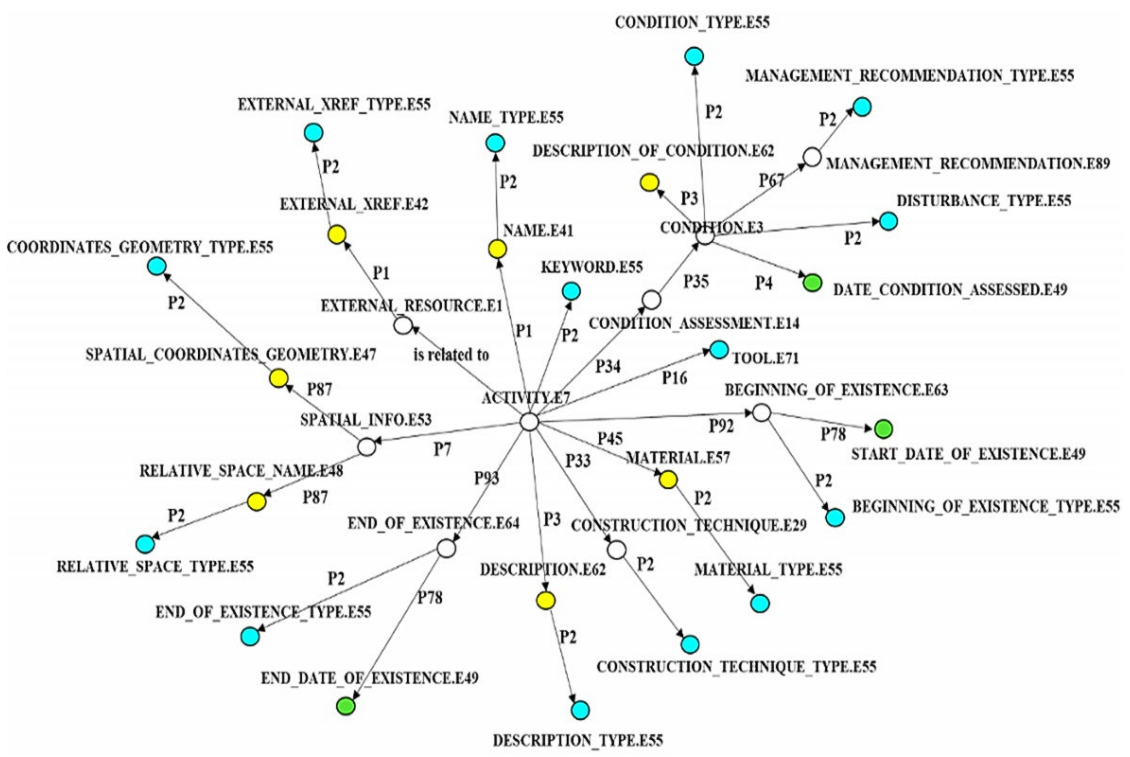

Figure 11. Overview of ontological model for restoration records 
Table 5. Basic information for building components

\begin{tabular}{|l|l|l|}
\hline \multicolumn{1}{|c|}{ Field title } & \multicolumn{1}{|c|}{ Definition } & \multicolumn{1}{c|}{ Example for data entry } \\
\hline Model ID & ID for the 3D model of building components & - \\
\hline Name & Name of building component & $\begin{array}{l}\text { Dou (supporting bracket), zuzhu (column } \\
\text { base), gong (bow-shaped bracket) }\end{array}$ \\
\hline Spatial location & The space which the building occupies & $\begin{array}{l}\text { Relative spatial location } \\
\text { Absolute spatial location }\end{array}$ \\
\hline Materials & Material of building component & Wood, brick, stone \\
\hline 3D & Dimensions of building component & Length x width x height \\
\hline Descriptions & $\begin{array}{l}\text { Descriptive information about the building } \\
\text { component }\end{array}$ & $\begin{array}{l}\text { Surface treatment } \\
\text { Cultural value }\end{array}$ \\
\hline $\begin{array}{l}\text { Audio and video attributes of } \\
\text { building component }\end{array}$ & $\begin{array}{l}\text { Audio and video records which help users fully } \\
\text { understand actual conditions }\end{array}$ & $\begin{array}{l}\text { Storage location and web address for the audio } \\
\text { and video files }\end{array}$ \\
\hline Time & $\begin{array}{l}\text { Time information related to the building } \\
\text { component }\end{array}$ & $\begin{array}{l}\text { Date of creation } \\
\text { Date of restoration }\end{array}$ \\
\hline
\end{tabular}

Table 6. Restoration information for building components

\begin{tabular}{|l|l|l|}
\hline \multicolumn{1}{|c|}{ Name of field } & \multicolumn{1}{|c|}{ Definition } & \multicolumn{1}{c|}{ Example for data entry } \\
\hline $\begin{array}{l}\text { Coding for restoration } \\
\text { records }\end{array}$ & $\begin{array}{l}\text { Coding for information related to restoration } \\
\text { of building components }\end{array}$ & - \\
\hline Time & $\begin{array}{l}\text { Schedule for restoration of building } \\
\text { components }\end{array}$ & $\begin{array}{l}\text { Research and survey stage, planning and design } \\
\text { stage, subcontracting, etc. }\end{array}$ \\
\hline Degree of damage & Evaluate degree of damages prior to restoration & Rooftop damages, wood damages \\
\hline Main construction method & Construction methods used during restoration & Principles and construction methods for restoration \\
\hline Tool & Tools used for this project & Chisels, scroll saw, sharpening stone, power drill. \\
\hline Material & Materials used for this project & $\begin{array}{l}\text { Red tile, flat tile, ceramic shard pasting decoration, } \\
\text { etc. }\end{array}$ \\
\hline $\begin{array}{l}\text { Link to construction records } \\
\text { or audio and video files }\end{array}$ & $\begin{array}{l}\text { Link to records, audio and video information } \\
\text { documented during construction }\end{array}$ & $\begin{array}{l}\text { The website or physical address of where the files } \\
\text { are stored }\end{array}$ \\
\hline Link to work report & $\begin{array}{l}\text { Link to the work report for construction } \\
\text { project }\end{array}$ & \\
\hline
\end{tabular}

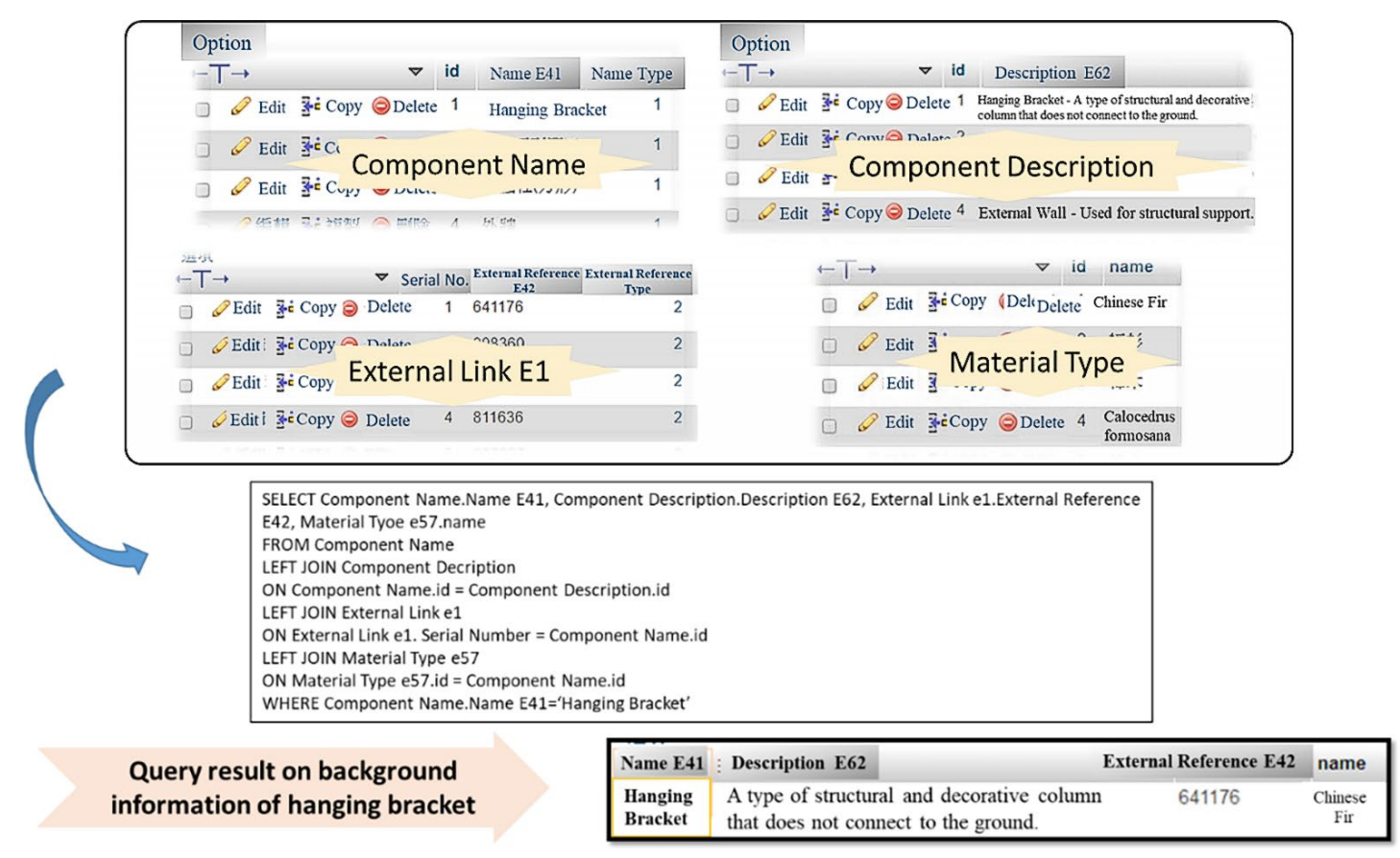

Figure 12. SQL query - background information for hanging bracket 

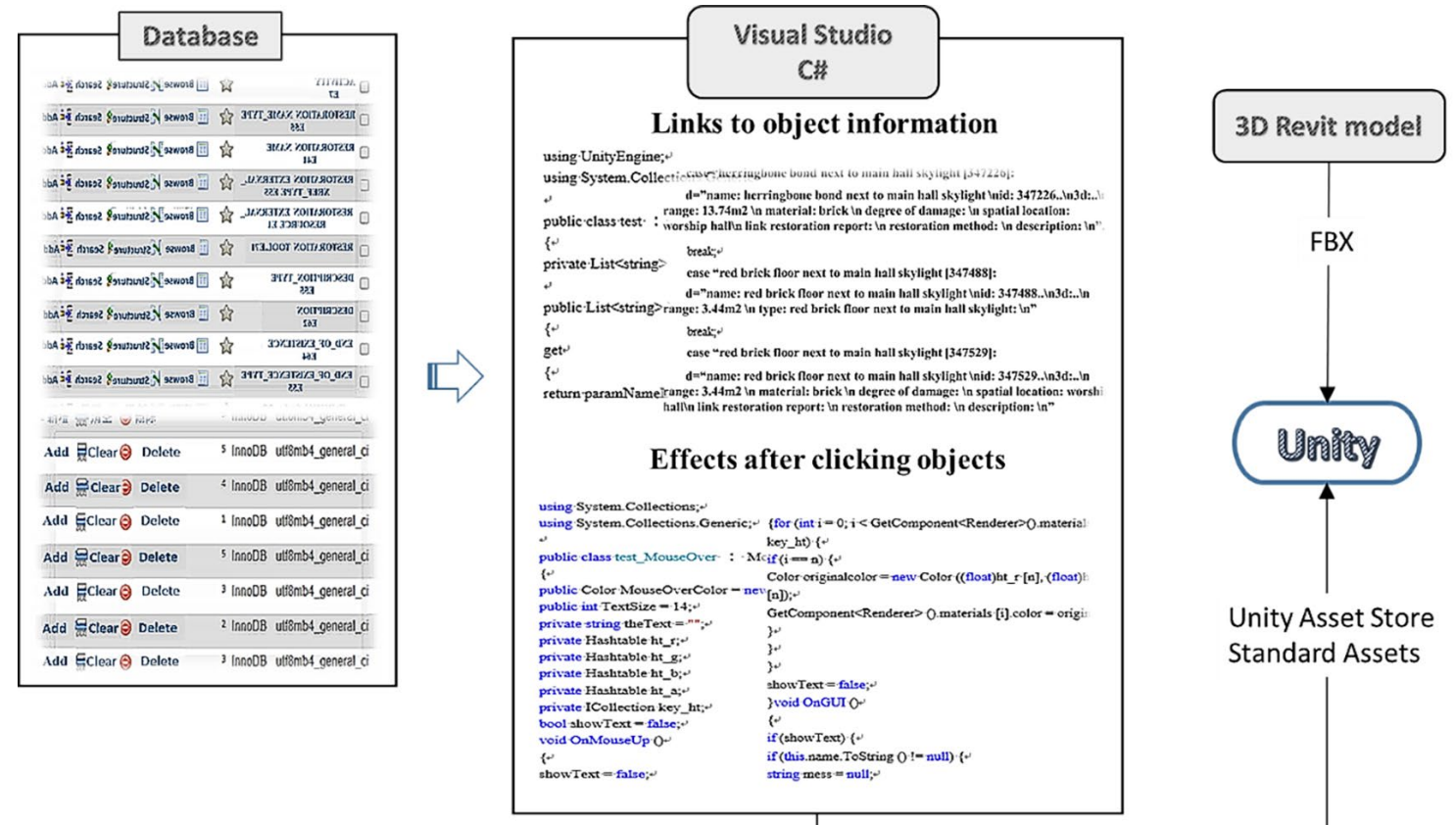

Unity Asset Store Standard Assets

Figure 13. Flowchart of platform establishment

In addition to the computer program, an Android application is also developed to accommodate the VR technology. The process is similar to the one previously described (applicable to Unity 2017). However, during the initial setting, users should choose Android as the platform, and under the player setting, choose Google Cardboard as VR support under XR Setting. Lastly, choose the appropriate items under Resolution and Presentation (as shown in Figure 14).

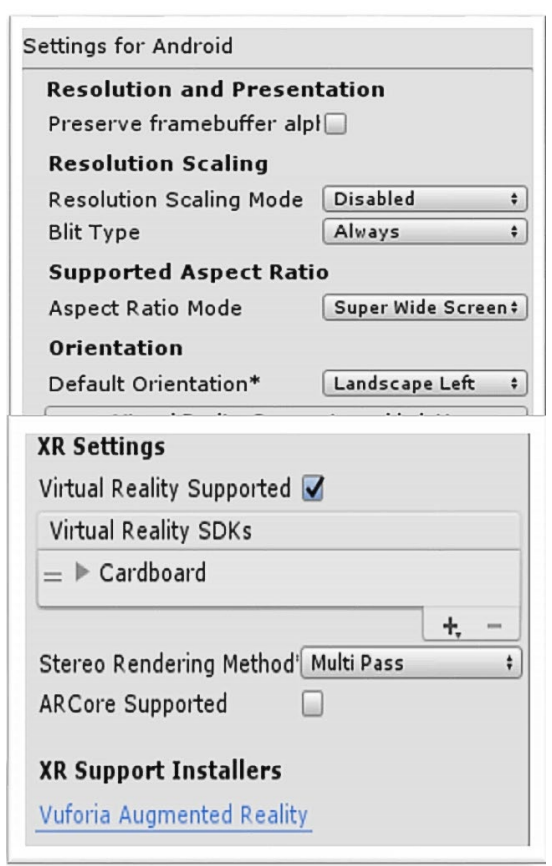

Figure 14. XR Settings \& Android settings for resolution and presentation
During the research process, three.js (https://threejs. org/) was also used to develop a similar system, but the system was applied towards another traditional Minan historic building (Cai Ancestral Shrines in Qionglin). The software, three.js, is a cross-browser open source JavaScript library and application programming interface (API) that is developed based on WebGL. It is used to display $3 \mathrm{D}$ models and for information visualization. Being open source allows for added flexibility. However, users must have programming capability. The technology used during the development of the three.js platform includes 3D model conversion, database data conversion and the generation of semantic data. In order to integrate the $3 \mathrm{D}$ model with the webpage, and make the 3D model created for this study viewable on the website, the 3D model is converted to XML based data exchange format (also ISO standard) - COLLADA (https://www.khronos.org/ collada/) with DAE extension. The database content for the historic building and restoration data are established in accordance with the Minan architectural components and restoration data analyzed in the previous section. The program for generating semantic data is developed with PHP based on ontology ( ${ }^{\star}$.owl) to convert the content in the database into semantic with meanings and RDF data that can be linked. For additional details, please refer to Kuo et al. (2018).

Autodesk A360 is a program developed specifically for architects, civil engineers and designers. A360 is compatible with over $100 \mathrm{CAD}$ files and other formats, such as RVT, NWD, DWG and DXF. Regardless of the software used to create the initial file, the file can be uploaded to A360 for review. Within the model, the single component will display characteristics of the component established 
in Revit, and users can view Huangxi Academy through the first-person camera view.

All of the finalized platforms from this research are shown in Figure 15. Users may click on the components for relevant data in the platforms developed with Unity and three.js, which is similar to the functions of A360. However, in Unity and three.js, the data fields are established with ontology/CIDOC CRM. Such approach is better aligned with international practice and leaves room for future expansion, which is appropriate for various types of historic structures, such as temples, churches and fortresses when such need arises. Additionally, since the database is not created as a Revit file, users may conduct queries such as the query on the background information of hanging bracket through MySQL, as shown in Figure 12.

a) Unity platform - query result 1

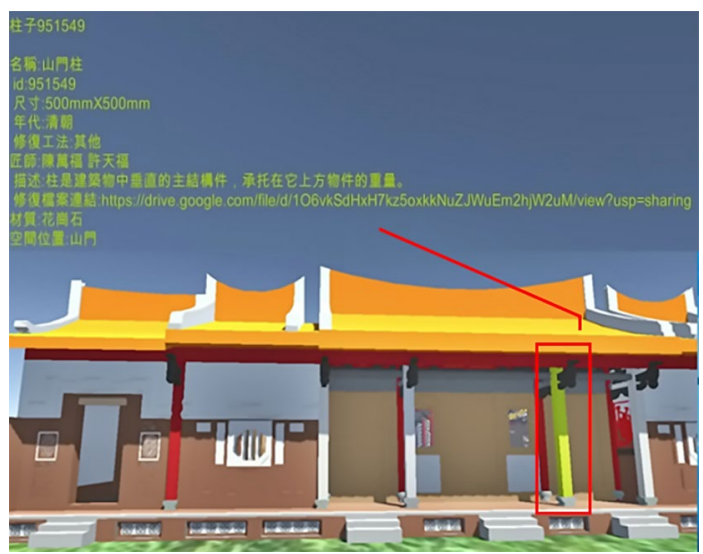

c) three.js platform - query result 1

Source: Cheng et al. (2018b)
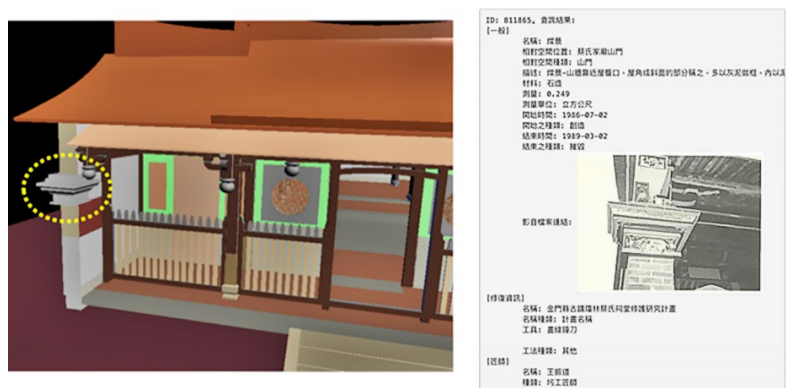

The 3D model is linked with the database through the component id, which minimizes the need to import all relevant data into Revit, and therefore reduces the Revit file size. The A360 platform is the most intuitive and convenient in terms of browsing, which can be done as soon as the model is uploaded. Programming is not a necessary capability for users. However, there are limitations when it comes to further applications of the $3 \mathrm{D}$ model, such as advanced visualization for fire prevention or immersion experience, as well as data maintenance and update. As to three.js, since it is open source, users may customize the interface to suit individual needs. However, it takes decent programming ability to create an ideal interface. In terms of Unity, which is a gaming platform, may be further developed to enhance user interaction or to be ap- b) Unity platform - query result 2

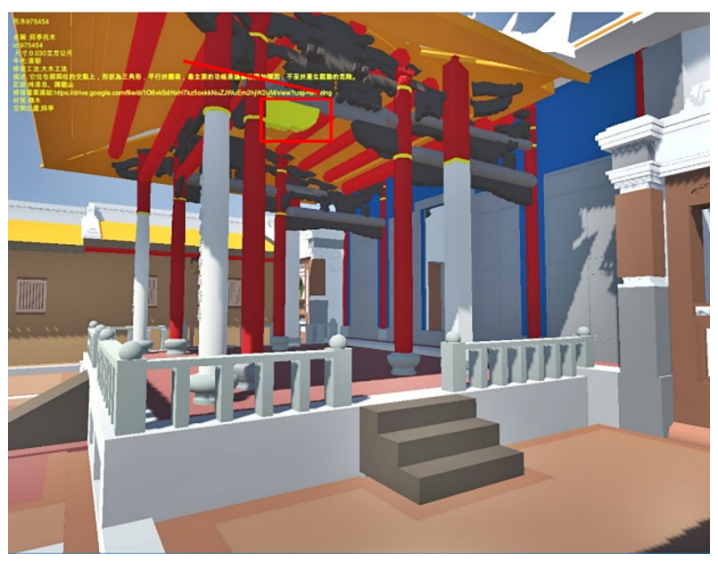

d) three.js platform - query result 2

Source: Cheng et al. (2018b)
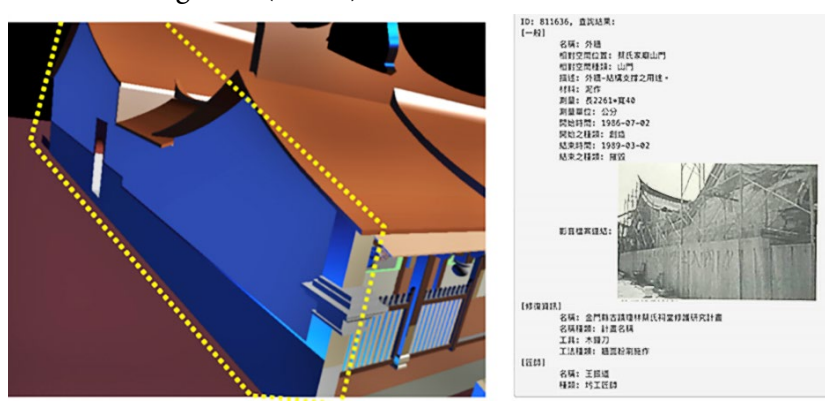

e) Finalized platform (VR)

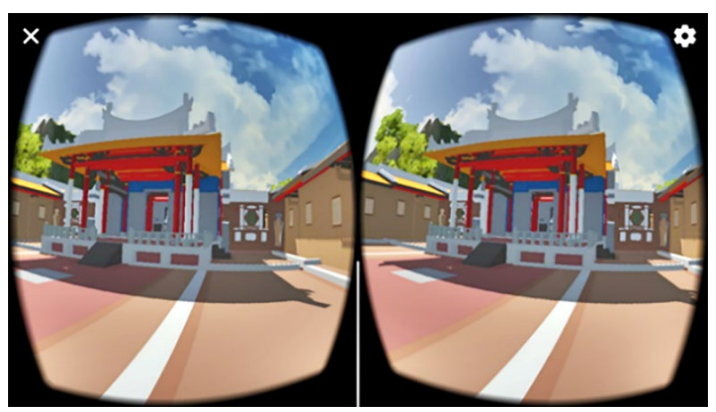

f) A360 browsing platform

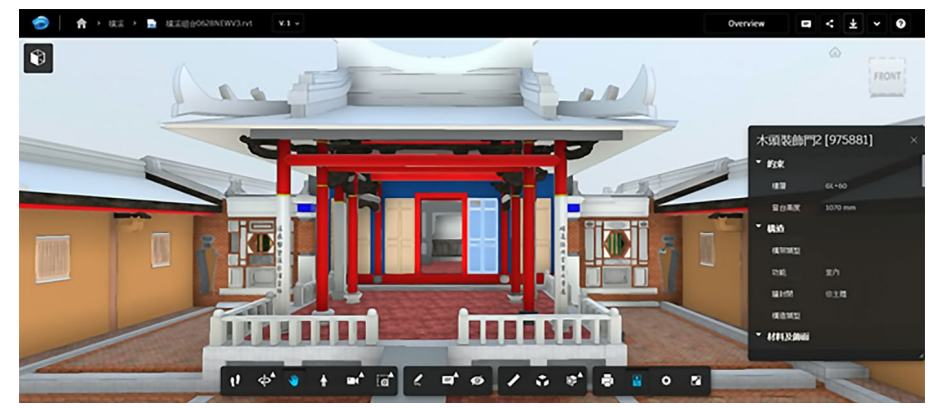

Figure 15. Finalized platform 
plied toward disaster relief drills. Aside from data query toward historic conservation, it has potential in applications toward 3D modeling for historic buildings. Details of the comparison of the three platforms are provided in Table 7 .

Table 7. Platform comparison

\begin{tabular}{|l|c|c|c|}
\hline \multicolumn{1}{|c|}{ Item } & A360 & Unity & three.js \\
\hline Technical limitations & Low & Medium & High \\
\hline Convenience & High & Medium & Low \\
\hline Future development & Medium & High & High \\
\hline $\begin{array}{l}\text { Viewable model } \\
\text { information }\end{array}$ & Yes & Yes & Yes \\
\hline $\begin{array}{l}\text { Flexibility and } \\
\text { expandability of database }\end{array}$ & Low & Medium & High \\
\hline $\begin{array}{l}\text { Rendering of model } \\
\text { exterior }\end{array}$ & Medium & High & Low \\
\hline
\end{tabular}

\section{Conclusions}

Rapid technological development has taken conservation techniques and documentation of restoration records for historic structures beyond the conventional approaches in surveying, drawing and reporting. Using digital modeling, building exteriors, restoration techniques and overall information on building components are documented. In the event that the historic structures are damaged, the digital model may serve as a key reference during restoration, which also enhances the value of digital archiving for historic buildings. The study proposes a comprehensive framework and operational procedure for the modeling of traditional Minan architecture. The research process incorporates BIM, CIDOC CRM ontological model, game engine and database building techniques. By integrating current information technology, the study explores the digitization of historic building components of Huangxi Academy, a traditional Minan wooden architecture located in central Taiwan. The 3D model of Huangxi Academy is constructed with Autodesk Revit, the ontological models are then built and analyzed using CIDOC CRM and Protégé, while the database is established through phpMyadmin. The outcomes from the process mentioned above are finalized and presented in the 3D platform established in Unity. Lastly, a comparison is conducted to evaluate the platforms built within Unity, three.js and Autodesk A360. To examine the building components of a traditional Minan wooden architecture, a systematic analysis is conducted. The components are examined individually with attributes clearly defined when they are converted to the $3 \mathrm{D}$ model. The components are positioned and categorized into parametric and non-parametric component database for more efficient analysis. Using the framework of CIDOC CRM to establish the content and context of information related to the historic building helps users establish an ontological model containing restoration records and quickly understand the information framework. The process also allows flexibility for future expansion of the database and ontological model. It is believed that this framework will be able to accommodate the documentation and deductive reasoning of pertinent information regarding historic buildings as time progresses. Applications of the process developed in this paper and its outcome go beyond traditional wooden architecture. They are also applicable toward studies of ancestral shrines, temples and fortresses, and the database developed may also serve as a reference for future modeling.

Establishing digital archives of historic buildings has been widely recognized as an eminent task, and it is made possible with the development of HBIM. Technological advances have introduced automated and semi-automated technologies to the field. However, due to budget concerns or the lack of fully-developed supporting technology, it is difficult for the authority to access and adopt cutting-edge technology immediately, or to create digital models of historic buildings containing background and restoration data that can be readily available for the general public. Rather than waiting for the funding or for the supporting technology to mature, it would be more practical to take advantage of existing technology, which is developed and accessible at a relatively low cost. This rationale gives way to why this study focuses on the logic and process behind manual 3D modeling. In terms of the data embedded within each component, the study concentrates on establishing a systematic approach with the possibility of future expansion while staying connected to international practice. Recommendations are provided in terms of methodology and software application. To choose the proper tools and LoD for the modeling, those in the field of heritage conservation must base their decisions on actual needs and available funding. In the case of conducting structural analysis to determine safety requirements, the LoD of the model would be crucial. However, it would not be the case for documentation purposes. LoD 300, as recommended in this study, would suffice for documenting information regarding building components. The study reveals that the higher the familiarity with software operation, the more efficient users become when building structural components with unique physical configurations for the Minan historic wooden structures. This is partly due to one's familiarity with the software, and partly because one can choose existing components with similar configurations from the database to modify, which is much less time-consuming. Actually, placing the components at the proper position is a relatively lengthier operation comparing to others during the entire process, which is why in addition to referring back to the floor plan and elevation drawings provided by the Center for Cultural Sites Rehabilitation and Development, point cloud is also incorporated to determine the precise location for the components. Looking into the future, automated positioning system or the development of such system would be research directions worth further efforts. 


\section{Acknowledgements}

This study is sponsored by the Bureau of Cultural Heritage, Ministry of Cultural for 2018 Research and Development Project Plan (107-5). The author would like to thank all participating experts, especially Ya-Ning Yen and the center for cultural sites rehabilitation and development. Without their valuable contributions, this research would not have been made possible.

\section{Author contributions}

Dr. Cheng conceived and performed the research and wrote the manuscript. Dr. Kuo helped to supervise the process of ontology modeling. Mr. Mou built the models and the Unity browsing platform.

\section{Disclosure statement}

The authors have no affiliations with or involvement in any organization or entity with any financial interest or non-financial interest in the subject matter or materials discussed in this manuscript.

\section{References}

Acierno, M., Cursi, S., Simeone, D., \& Fiorani, D. (2017). Architectural heritage knowledge modelling: An ontology-based framework for conservation process. Journal of Cultural Heritage, 24, 124-133. https://doi.org/10.1016/j.culher.2016.09.010

Antón, D., Medjdoub, B., Shrahily, R., \& Moyano, J. (2018). Accuracy evaluation of the semi-automatic $3 \mathrm{D}$ modeling for historical building information models. International Journal of Architectural Heritage, 12(5), 790-805. https://doi.org/10.1080/15583058.2017.1415391

Antón, D., Pineda, P., Medjdoub, B., \& Iranzo, A. (2019). As-built $3 \mathrm{D}$ heritage city modelling to support numerical structural analysis: Application to the assessment of an archaeological remain. Remote Sensing, 11(11), 1276. https://doi.org/10.3390/rs11111276

Antonopoulou, S., \& Bryan, P. (2017). BIM for heritage: developing a historic building information model. Historic England.

Banfi, F. (2017). BIM orientation: Grades of generation and information for different type of analysis and management process. International Archives of the Photogrammetry, Remote Sensing and Spatial Information Sciences, XLII-2/W5, 57-64. https://doi.org/10.5194/isprs-archives-XLII-2-W5-57-2017

Banfi, F., Fai, S., \& Brumana, R. (2017). BIM automation: Advanced modeling generative process for complex structures. ISPRS Annals of The Photogrammetry, Remote Sensing and Spatial Information Sciences, IV-2/W2, 9-16.

https://doi.org/10.5194/isprs-annals-IV-2-W2-9-2017

Barazzetti, L. (2016). Parametric as-built model generation of complex shapes from point clouds. Advanced Engineering Informatics, 30, 298-311.

https://doi.org/10.1016/j.aei.2016.03.005

Barazzetti, L., Brumana, R., Oreni, D., Previtali, M., \& Roncoroni, M. (2014). True-orthophoto generation from UAV images: Implementation of a combined photogrammetric and computer vision approach. ISPRS Annals of The Photogrammetry, Remote Sensing and Spatial Information Sciences, II-5, 57-63. https://doi.org/10.5194/isprsannals-II-5-57-2014
Barazzetti, L., Mezzino, D., \& Quintero, M. S. (2017). Digital workflow for the conservation of Bahrain built heritage: The Sheik Isa Bin Ali House. International Archives of the Photogrammetry, Remote Sensing and Spatial Information Sciences, XLII-2/W5, 65-70.

https://doi.org/10.5194/isprs-archives-XLII-2-W5-65-2017

Boeykens, S., Himpe, C., \& Martens, B. (2012). A case study of using BIM in historical reconstruction. The Vinohrady Synagogue in Prague. eCAADe 30 (Virtual Architecture), 1, 729-738.

Brumana, R., Oreni, D., Raimondi, A., Georgopoulos, A., \& Bregianni, A. (2013, October). From survey to HBIM for documentation, dissemination and management of built heritage: The case study of St. Maria in Scaria d'Intelvi. Digital Heritage International Congress (Digital Heritage), 1, 497-504. https://doi.org/10.1109/DigitalHeritage.2013.6743789

Brumana, R., Oreni, D., Torre, S. D., Banfi. F, Barazzetti, L., \& Previtali, M. (2014). Survey turned Into BIM: The restoration and the work involved concerning the Basilica Di Collemaggio after the earthquake. ISPRS Annals of the Photogrammetry, Remote Sensing and Spatial Information Sciences, II-5, 267-273. https://doi.org/10.5194/isprsannals-II-5-267-2014

Buonamici, F., Carfagni, M., Furferi, R., Governi, L., Lapini, A., \& Volpe, Y. (2018). Reverse engineering modeling methods and tools: a survey. Computer-Aided Design and Applications, 15(3), 443-464. https://doi.org/10.1080/16864360.2017.1397894

Cheng, Y. M., Mou, C. C., Lu, Y. C., \& Yen, Y. N. (2018a). HBIM in cultural heritage conservation component library for woodwork in historic buildings in Taiwan. Springer International Publishing. https://doi.org/10.1007/978-3-030-01762-0_32

Cheng, Y. M., Yen, Y. N., Kuo, C. L., Mou, C. C., \& Lu, Y. C. (2018b). Research on the application of HBIM in the preservation of cultural assets (I) - taking the Southern Fujian-style wooden architecture as an example. Bureau of Cultural Heritage, Ministry of Culture, Taiwan.

Chiabrando, F., Sammartano, G., \& Spanò, A. (2016). Historical buildings models and their handling via 3D survey: From points clouds to user-oriented HBIM. The International Archives of the Photogrammetry, Remote Sensing and Spatial Information Sciences, XLI-B5, 633-640.

https://doi.org/10.5194/isprsarchives-XLI-B5-633-2016

Dezen-Kempter, E., Cogima, C. K., de Paiva, P. V. V., \& de Carvalho, M. A. G. (2018). BIM for heritage documentation: An ontology-based approach. eCAADe 36 (BIM Applications), 1, 213-222.

Dhanda, A., Fai, S., Graham, K., \& Walczak, G. (2017). Leveraging existing heritage documentation for animations: Senate virtual tour. International Archives of the Photogrammetry, Remote Sensing and Spatial Information Sciences, XLII-2/W5, 171-175.

https://doi.org/10.5194/isprs-archives-XLII-2-W5-171-2017

Fadli, F., \& AlSaeed, M. (2019). Digitizing vanishing architectural heritage; The design and development of Qatar historic buildings information modeling [Q-HBIM] platform. Sustainability, 11, 2501. https://doi.org/10.3390/su11092501

Fregonese, L., Achille, C., Adami, A., Fassi, F., Spezzoni, A., \& Taffurelli, L. (2015). BIM: An integrated model for planned and preventive maintenance of architectural heritage. 2015 Digital Heritage, 2, 77-80. IEEE. https://doi.org/10.1109/DigitalHeritage.2015.7419456

Han, S., Wu, C., Li, D., Li, J., Liu, Y., Feng, K., \& Di, Y. (2017). Workflows for condition inspection documentation of architectural heritage based on HBIM: Taking three duty rooms in Forbidden City of Beijing as an example. ISPRS Annals of 
the Photogrammetry, Remote Sensing and Spatial Information Sciences, $I V-2 / W 2,123-129$.

https://doi.org/10.5194/isprs-annals-IV-2-W2-123-2017

Hichri, N., Stefani, C., De Luca, L., Veron, P., \& Hamon, G. (2013). From Point Cloud to BIM: A survey of existing approaches. International Archives of the Photogrammetry, Remote Sensing and Spatial Information Sciences, XL-5/W2, 343-348. https://doi.org/10.5194/isprsarchives-XL-5-W2-343-2013

International Organization for Standardization. (2006). Information and documentation - A reference ontology for the interchange of cultural heritage information (ISO Standard No. 21127:2006). https://www.iso.org/standard/34424.html

International Organization for Standardization. (2014). Information and documentation - A reference ontology for the interchange of cultural heritage information (ISO Standard No. ISO 21127:2014). https://www.iso.org/standard/57832.html

Kuo, C.-L., Cheng, Y.-M., Lu, Y.-C., Lin, Y.-C., Yang, W.-B., \& Yen, Y.-N. (2018). A framework for semantic interoperability in 3D tangible cultural heritage in Taiwan. In EuroMED 2018, Cyprus. https://doi.org/10.1007/978-3-030-01765-1_3

Lee, C. L. (2003). Guji Tujieshidian (A Pictorial Guide for Historic Sites).

Logothetis, S., \& Stylianidis, E. (2016). BIM open source software (Oss) for the documentation of cultural heritage. Virtual Archaeology Review, 7(15), 28-35.

https://doi.org/10.4995/var.2016.5864

Logothetis, S., Delinasiou, A., \& Stylianidis, E. (2015). Building information modelling for cultural heritage: A review. ISPRS Annals of Photogrammetry, Remote Sensing and Spatial Information Sciences, II-5/W3, 177-183.

https://doi.org/10.5194/isprsannals-II-5-W3-177-2015

López, F. J., Lerones, P. M., Llamas, J., Gómez-García-Bermejo, J., \& Zalama, E. (2018). A review of heritage building information modeling (H-BIM). Multimodal Technologies and Interaction, 2(2), 21. https://doi.org/10.3390/mti2020021

Moyano, J., Odriozola, C. P., Nieto-Julián, J. E., Vargas, J. M., Barrera, J. A., \& León, J. (2020). Bringing BIM to archaeological heritage: Interdisciplinary method/strategy and accuracy applied to a megalithic monument of the Copper Age. Journal of Cultural Heritage, 45, 303-314.

https://doi.org/10.1016/j.culher.2020.03.010

Murphy, M., McGovern, E., \& Pavia, S. (2009). Historic building information modelling (HBIM). Structural Survey, 27(4), 311-327. https://doi.org/10.1108/02630800910985108

National Cultural Heritage Database Management System. (2020). https://nchdb.boch.gov.tw/assets/overview/monument/19851127000003

Nieto Julián, J. E., Campos, J. J. M., Delgado, F. R., \& García, D. A. (2016). Management of built heritage via HBIM Project: A case of study of flooring and tiling. Virtual Archaeology Review, 7(14), 1-12. https://doi.org/10.4995/var.2016.4349

Pöchtrager, M., Styhler-Aydın, G., Döring-Williams, M., \& Pfeifer, N. (2017). Automated reconstruction of historic roof structures from point clouds - Development and examples. ISPRS Annals of the Photogrammetry, Remote Sensing and Spatial Information Sciences, IV-2/W2, 195-202.

https://doi.org/10.5194/isprs-annals-IV-2-W2-195-2017

Previtali, M., Brumana, R., Stanga, C., \& Banfi, F. (2020). An ontology-based representation of vaulted system for HBIM. Applied Sciences, 10, 1377. https://doi.org/10.3390/app10041377

Quattrini, R., Pierdicca, R., \& Morbidoni, C. (2017). Knowledgebased data enrichment for HBIM: Exploring high-quality models using the semantic-web. Journal of Cultural Heritage, 28, 129-139. https://doi.org/10.1016/j.culher.2017.05.004
Tang, P., Huber, D., Akinci, B., Lipman, R., \& Lytle, A. (2010). Automatic reconstruction of as-built building information models from laser-scanned point clouds: A review of related techniques. Automation in Construction, 19(7), 829-843. https://doi.org/10.1016/j.autcon.2010.06.007

Thomson, C., \& Boehm, J. (2015). Automatic geometry generation from Point Clouds for BIM. Remote Sensing, 7(9), 11753-11775. https://doi.org/10.3390/rs70911753

UNESCO. (2020). New inscribed properties (2019). https://whc. unesco.org/en/newproperties/?date $=2019 \&$ mode=list\&inscri bed $=1$

Volk, R., Stengel, J., \& Schultmann, F. (2014). Building Information Modeling (BIM) for existing buildings - Literature review and future needs. Automation in Construction, 38, 109-127. https://doi.org/10.1016/j.autcon.2013.10.023

Yen, Y. N. (2018). Restoration and reuse plan for Huangxi Academy, a municipal historic site. Bureau of Cultural Heritage, Ministry of Culture, Taiwan.

Yen, Y. N., \& Lu, Y. C. (2019). Research on HBIM and level of information for the life cycle of traditional Chinese built heritage in Taiwan. The International Archives of the Photogrammetry, Remote Sensing and Spatial Information Sciences, XLII-2/W11, 1159-1163.

https://doi.org/10.5194/isprs-archives-XLII-2-W11-1159-2019 